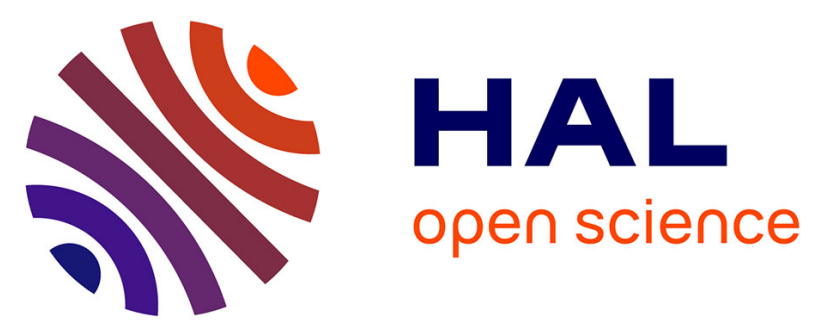

\title{
Properties of water ice and dust particles in the atmosphere of Mars during the 2018 global dust storm as inferred from the Atmospheric Chemistry Suite
}

Mikhail Luginin, A. Fedorova, N. Ignatiev, A. Trokhimovskiy, A. Shakun, A. Grigoriev, A. Patrakeev, Franck Montmessin, O. Korablev

\section{To cite this version:}

Mikhail Luginin, A. Fedorova, N. Ignatiev, A. Trokhimovskiy, A. Shakun, et al.. Properties of water ice and dust particles in the atmosphere of Mars during the 2018 global dust storm as inferred from the Atmospheric Chemistry Suite. Journal of Geophysical Research. Planets, 2020, 125 (11), pp.e2020JE006419. 10.1029/2020JE006419 . insu-02955541

\section{HAL Id: insu-02955541 \\ https://hal-insu.archives-ouvertes.fr/insu-02955541}

Submitted on 4 Mar 2021

HAL is a multi-disciplinary open access archive for the deposit and dissemination of scientific research documents, whether they are published or not. The documents may come from teaching and research institutions in France or abroad, or from public or private research centers.
L'archive ouverte pluridisciplinaire HAL, est destinée au dépôt et à la diffusion de documents scientifiques de niveau recherche, publiés ou non, émanant des établissements d'enseignement et de recherche français ou étrangers, des laboratoires publics ou privés. 


\section{JGR Planets}

\section{RESEARCH ARTICLE \\ 10.1029/2020JE006419 \\ Key Points: \\ - Atmospheric Chemistry Suite solar occultations in the 0.7-6 $\mu \mathrm{m}$ spectral range separate microphysical properties of dust and water ice aerosols in Martian atmosphere \\ - The observed particle radius ranges from 0.1 to $3.5 \mu \mathrm{m}$ for dust and from 0.1 to $5.5 \mu \mathrm{m}$ for water ice clouds, with the largest particles found below $10 \mathrm{~km}$ \\ - Water ice clouds with 0.1-1 $\mu \mathrm{m}$ particles reached altitudes up to $100 \mathrm{~km}$ during the peak of the 2018 global dust storm}

Correspondence to:

M. Luginin,

mikhail.luginin@phystech.edu

Citation:

Luginin, M., Fedorova, A., Ignatiev, N., Trokhimovskiy, A., Shakun, A., Grigoriev, A., et al. (2020). Properties of water ice and dust particles in the atmosphere of mars during the 2018 global dust storm as inferred from the atmospheric chemistry suite. Journal of Geophysical Research: Planets, e2020JE006419. https://doi. org/10.1029/2020JE006419

Received 19 FEB 2020 Accepted 28 SEP 2020

\section{Properties of Water Ice and Dust Particles in the Atmosphere of Mars During the 2018 Global Dust Storm as Inferred From the Atmospheric Chemistry Suite}

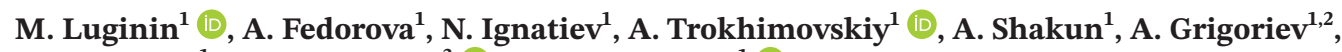 \\ A. Patrakeev ${ }^{1}$, F. Montmessin ${ }^{3}$ (D) , and O. Korablev ${ }^{1}$ (D) \\ ${ }^{1}$ Space Research Institute (IKI), Moscow, Russia, ${ }^{2}$ Australian National University (ANU), Canberra, Australia, \\ ${ }^{3}$ LATMOS, UVSQ Université Paris-Saclay, Sorbonne Université, CNRS, Paris, France
}

\begin{abstract}
The properties of Martian aerosols are an integral part of the planetary climatology. Global dust storms (GDS) significantly alter spatial and vertical distributions of dust and water ice aerosols and their microphysical properties. We explored the 2018/Martian year 34 GDS with the Atmospheric Chemistry Suite instrument onboard the ESA-Roscosmos Trace Gas Orbiter mission. Solar occultation observations of thermal infrared and near infrared channels in the 0.7-6 $\mu \mathrm{m}$ spectral range with $>10^{3}$ signal-to-noise ratio are used to constrain the vertical dependence and the temporal evolution of the particle properties of water ice and dust (effective radius, effective variance, number density, and mass loading) before the 2018 GDS and during its onset and decay phases. In most of the observations, the particle size of dust and water ice decreases with altitude. The effective radius of dust and water ice particles ranges in $0.1-3.5 \mu \mathrm{m}$ and $0.1-5.5 \mu \mathrm{m}$, respectively. The largest aerosol particles ( $>2.5 \mu \mathrm{m}$ for dust and $>3.5 \mu \mathrm{m}$ for water ice) are present below $10 \mathrm{~km}$ before the onset and during the GDS decay phase. During the peak of the GDS, dust reached altitudes of $85 \mathrm{~km}$; the most frequently observed effective radius is $1-2 \mu \mathrm{m}$ with $0.1-1 \mathrm{~cm}^{-3}$ number density and 0.1 effective variance. Detached layers of water ice composed of 0.1-1 $\mu \mathrm{m}$ particles are systematically observed at 50-100 km during this period. Below, at $0-50 \mathrm{~km}$, we see the dust mixed with the main water ice layer comprising 1-4 $\mu \mathrm{m}$ particles.
\end{abstract}

Plain Language Summary Suspended in the air, mineral dust and water ice particles play a key role in thermal balance and circulation of the atmosphere of Mars and its climate. In that context, global dust storms are rare but powerful events that significantly alter spatial and vertical distributions of dust and water ice particles and their properties. The most recent event, which occurred in the summer of 2018, was monitored by the Atmospheric Chemistry Suite instrument onboard the ESA-Roscosmos Trace Gas Orbiter mission. Solar occultation observations carried out in the visible and the middle infrared spectral ranges enabled monitoring of dust and water ice particles properties such as size, number of particles and their mass per unit volume, and the width of their size distribution during the evolution of the storm. Dust was lifted to $85 \mathrm{~km}$, while water ice clouds were observed at even higher altitudes, up to $100 \mathrm{~km}$.

\section{Introduction}

Dust and water ice aerosols play a major role in the energy budget and circulation of the atmosphere of Mars and its climate. Dust affects the thermal structure and the dynamics of the atmosphere. Water ice clouds play an important part in the water cycle by altering the global transport of water vapor (Montmessin et al., 2004; Richardson \& Wilson, 2002), by influencing the Martian climate radiatively (Madeleine et al., 2012; Wilson et al., 2008), and by changing the dust distribution through the scavenging of dust aerosols' particles due to the condensation of ice (Navarro et al., 2014; Pearl et al. 2001). Information on the aerosols physical properties is needed for a better understanding and modeling of Martian climate (Guzewich et al., 2013; Madeleine et al., 2012; Navarro et al., 2014; Shaposhnikov et al., 2018).

Global dust storms (hereafter GDS, also known as global dust events and planet-encircling dust events) are rare and still unpredictable phenomena on Mars happening during the southern spring/summer seasons on Mars from solar longitude $\left(L_{S}\right) 185^{\circ}$ to $300^{\circ}$. They typically occur one out of three Martian years (MY; Smith, 2008; Wang \& Richardson, 2015) and span several months (Cantor, 2007; Smith, 2009). The 2018 
GDS (corresponding to MY 34 according to the MY numbering proposed by Clancy et al. [2000]) started from two regional dust storms appearing at $L_{S} \simeq 181^{\circ}$ in the Northern hemisphere and at $L_{S} \simeq 188^{\circ}$ in the Southern hemisphere that later merged to become a full GDS at $L_{S} \simeq 193^{\circ}$ (Bertrand et al., 2020; Guzewich et al., 2019). Mars Climate Sounder (MCS) onboard the Mars Reconnaissance Orbiter (MRO) has observed one of these regional dust storms in Acidalia Planitia (Shirley et al., 2019).

GDS, through lifting and advection of dust, warm the atmosphere of Mars and modify atmospheric circulation as well as the $\mathrm{CO}_{2}$ and water cycles, and, thus, directly influence the distribution of dust and water ice aerosol particles in the atmosphere of Mars (Cantor, 2007; Conrath, 1975; Haberle et al., 1982; Leovy \& Zurek, 1979; Zurek, 1982).

At low and moderate dust conditions, values of dust effective radius $r_{\text {eff }}$ and effective variance $v_{\text {eff }}$ measured from the rovers and orbiters are in the range of $r_{\text {eff }}=1-2 \mu \mathrm{m}$ and $\nu_{\text {eff }}=0.2-0.4$ (see reviews in Clancy et al., 2019; Kahre et al., 2017; Korablev et al., 2005; Smith, 2008). During the GDSs, larger dust particles were observed: $r_{\text {eff }}=1.8-2.5 \mu \mathrm{m}$ during the 2001 (MY 25) GDS (Clancy et al., 2010) and $r_{\text {eff }}>4 \mu \mathrm{m}$ during the 2018 GDS (Lemmon et al., 2019). The effective radius and effective variance of water ice aerosols were constrained in the ranges of $r_{\text {eff }}=1-4 \mu \mathrm{m}$ and $v_{\text {eff }}=0.1-0.4$ throughout the MY (Chassefière et al., 1992; Clancy et al., 2019, 2003; Fedorova et al., 2009; Guzewich \& Smith, 2019; Guzewich et al, 2014; Korablev et al., 1993).

Vertical distribution of aerosols is of particular interest in modeling atmospheric circulation and climate of Mars. The IR channel of Spectroscopy for Investigation of Characteristics of the Atmosphere of Mars instrument (SPICAM-IR) onboard the Mars Express (MEx) spacecraft has already retrieved particle sizes and number densities of aerosols from solar occultation observations for more than 15 years (Fedorova et al., 2009; Määttänen et al., 2013; Montmessin et al., 2006, 2017), without the capability to distinguish between dust and water ice particles. OMEGA/MEx can retrieve the vertical structure of aerosols from limb images of the Martian atmosphere (Bibring et al., 2004; Vincendon et al., 2008). MCS/MRO produces data enabling the retrieval of dust and water ice vertical abundance in the form of extinction at specific thermal infrared wavelengths (Heavens et al., 2011; Kleinböhl et al., 2020, 2009; Montabone et al., 2015). Atmospheric Chemistry Suite (ACS) and Nadir and Occultation for Mars Discovery (NOMAD) instruments onboard Trace Gas Orbiter (TGO) permit the retrieval of vertical profiles of particle size distribution and the number density of aerosols from solar occultation observations (Fedorova et al., 2020; Vandaele et al., 2019).

In this study, we present the evolution of water ice and dust particle properties (vertical distributions of effective radius, effective variance, number density, and mass loading) during the 2018 GDS retrieved from ACS/TGO multiwavelength solar occultation observations in a broad spectral range. Section 2 contains a description of the instruments and analyzed data sets. In Section 3, retrieval methods for the aerosol extinction, effective radius, effective variance, number density, and mass loading are described. Results are then presented in Section 4. Section 5 gives a summary and a discussion of the major findings, with main conclusions of the work proposed in Section 6.

\section{Data Set}

The ExoMars TGO is a joint ESA-Roscosmos mission with a primary goal to study trace gases in Mars' atmosphere and provide long-term monitoring of the atmospheric composition and temperature (Vago et al., 2015). One of the instruments concerned with making these measurements is the ACS (Korablev et al., 2018). ACS is a set of three spectrometers (Near InfraRed [NIR], Mid-InfraRed [MIR], and TIRVIM) intended to observe Mars' atmosphere in solar occultations, nadir, and limb geometry.

\subsection{TIRVIM Instrument Description}

The TIRVIM (Thermal InfraRed in honor of Professor Vassily Ivanovich Moroz) channel is a Fourier-transform spectrometer based on a 2-in. double pendulum interferometer (Korablev et al., 2018; Shakun et al., 2018). Its concept is similar to that of the Planetary Fourier Spectrometer (Formisano et al., 2005) onboard MEx, while TIRVIM features a cryogenic detector and can observe in solar occultation together with other 
ACS channels. The most beneficial mode for aerosol properties retrieval proved to be the so-called climatology mode, essentially a nadir operation sequence with a solar occultation pointing. This mode provides a better signal-to-noise ratio (SNR) at the expense of lower spectral resolution. The full continuous spectral range of $1.7-17 \mu \mathrm{m}$ is recorded every $0.4 \mathrm{~s}$ with spectral resolution $\leq 1 \mathrm{~cm}^{-1}$.

To characterize aerosols, we use spectra obtained at 19 wavenumbers within the $1,760-5,030 \mathrm{~cm}^{-1}(2-6 \mu \mathrm{m})$ spectral range outside of strong gas absorption bands: 1,760, 2,510, 2,600, 2,700, 2,800, 2,900, 3,027, 3,072, $3,263,3,400,3,446,3,919,4,033,4,116,4,346,4,478,4,584,4,646$, and $5,030 \mathrm{~cm}^{-1}$. Wavenumbers at 3,027, $3,072,3,263,3,400$, and $3,446 \mathrm{~cm}^{-1}$ located inside the water ice absorption feature allow for an unambiguous separation of dust and water ice particles.

The full TIRVIM field of view (FOV) corresponds to a $2.8^{\circ}$ circle. During the solar occultation measurement, the effective FOV is limited by the solar disk diameter $\sim 0.35^{\circ}$ (typically $\sim 10 \mathrm{~km}$ at the limb). To increase the SNR, spectra are averaged using a moving average over a $50-\mathrm{cm}^{-1}$ spectral window and a $2-\mathrm{km}$ altitude window; the number of averaged spectral points depends on the altitude sampling and typically equals 400-800. After averaging, the resulting FOV of TIRVIM equals $\sim 12 \mathrm{~km}$. The typical value of SNR during TIRVIM solar occultation measurements is $\geq 10^{3}$. SNR changes over the spectral range due to spectral dependence of detector sensitivity; the ratio of SNR between the most and the least sensitive wavenumbers is $<2$.

\subsection{NIR Instrument Description}

The NIR channel is an echelle spectrometer with a selection of diffraction orders by an acousto-optical tunable filter (Korablev et al., 2018; Trokhimovsky et al., 2017). ACS NIR covers the 0.7-1.7 $\mu \mathrm{m}$ spectral range in diffraction orders 101 through 49 with a resolving power of $\lambda / \Delta \lambda \approx 25,000$. It observes Mars in nadir and solar occultation modes. During an occultation, NIR measures 10 preselected diffraction orders in $2 \mathrm{~s}$, mainly tuned to the absorption bands of $\mathrm{H}_{2} \mathrm{O}(1.13,1.38,1.40 \mu \mathrm{m})$ and $\mathrm{CO}_{2}(1.27,1.43,1.54,1.57 \mu \mathrm{m})$. Two orders $(0.86$ and $0.99 \mu \mathrm{m})$ are specifically dedicated to aerosols. The vertical FOV of NIR is limited by the slit width (1.2 arcmin) or $0.7 \mathrm{~km}$ at the limb. NIR typical vertical resolution is determined by the smearing of the FOV on the limb during the exposure time and the number of spectra averaged and is roughly equal to $1 \mathrm{~km}$.

To characterize aerosols, we use "aerosol" orders $78\left(10,052-10,170 \mathrm{~cm}^{-1}\right)$ and $90\left(11,500-11,734 \mathrm{~cm}^{-1}\right)$, with no strong gas absorption bands, as well as orders $49\left(6,316-6,389 \mathrm{~cm}^{-1}\right), 56\left(7,217-7,302 \mathrm{~cm}^{-1}\right)$, and $101\left(13,016-13,170 \mathrm{~cm}^{-1}\right)$ which contain $\mathrm{CO}_{2}, \mathrm{H}_{2} \mathrm{O}$, and $\mathrm{O}_{2}$ absorptions. $\mathrm{CO}_{2}$ density, temperature, and water vapor mixing ratio are retrieved from orders 49 and 56 (see Fedorova et al., 2020). To improve the SNR, 6-20 lines on the NIR detector are averaged, depending on the mode of observation.

During the solar occultation, the effective FOV of TIRVIM is several times larger than that of the NIR. We have applied a moving average over a 10-km window to NIR spectra profiles to simulate a coarser FOV of TIRVIM, which additionally improves the SNR by a factor of $\sim 2$. A typical value of SNR for ACS NIR solar occultation measurements is better than $10^{3}$.

\subsection{Observations}

TGO started its science operations in the near-circular 400-km orbit in April 2018, with the first occultation observed on 21 April 2018. In this work, we analyze the data acquired from 266 occultation sessions, from the first TIRVIM climatology occultation on 5 May $2018\left(L_{S}=170^{\circ}\right.$, orbit \#1990) until 22 September $2018\left(L_{S}\right.$ $=255^{\circ}$, orbit \#3706). In 135 occultations, TIRVIM observed simultaneously with NIR. Geographical coordinates of observations are intrinsically connected to the parameters of the spacecraft orbit. Figure 1 shows a map of all the observations analyzed in this work. A list of observations analyzed in this study, as well as other Supporting Information, is available to download, see "Data availability" section.

There were no solar occultations observations in the period from 2 until $12 \mathrm{July}\left(L_{S}=204^{\circ}-210^{\circ}\right)$ because of the unfavorable properties of TGO orbit in that period. From 16 July until 31 August $\left(L_{S}=216^{\circ}-242^{\circ}\right)$, TIRVIM was mostly not operating due to instrumental problems. During this period, only three occultations were carried out, on 21 July and on 5 August. 

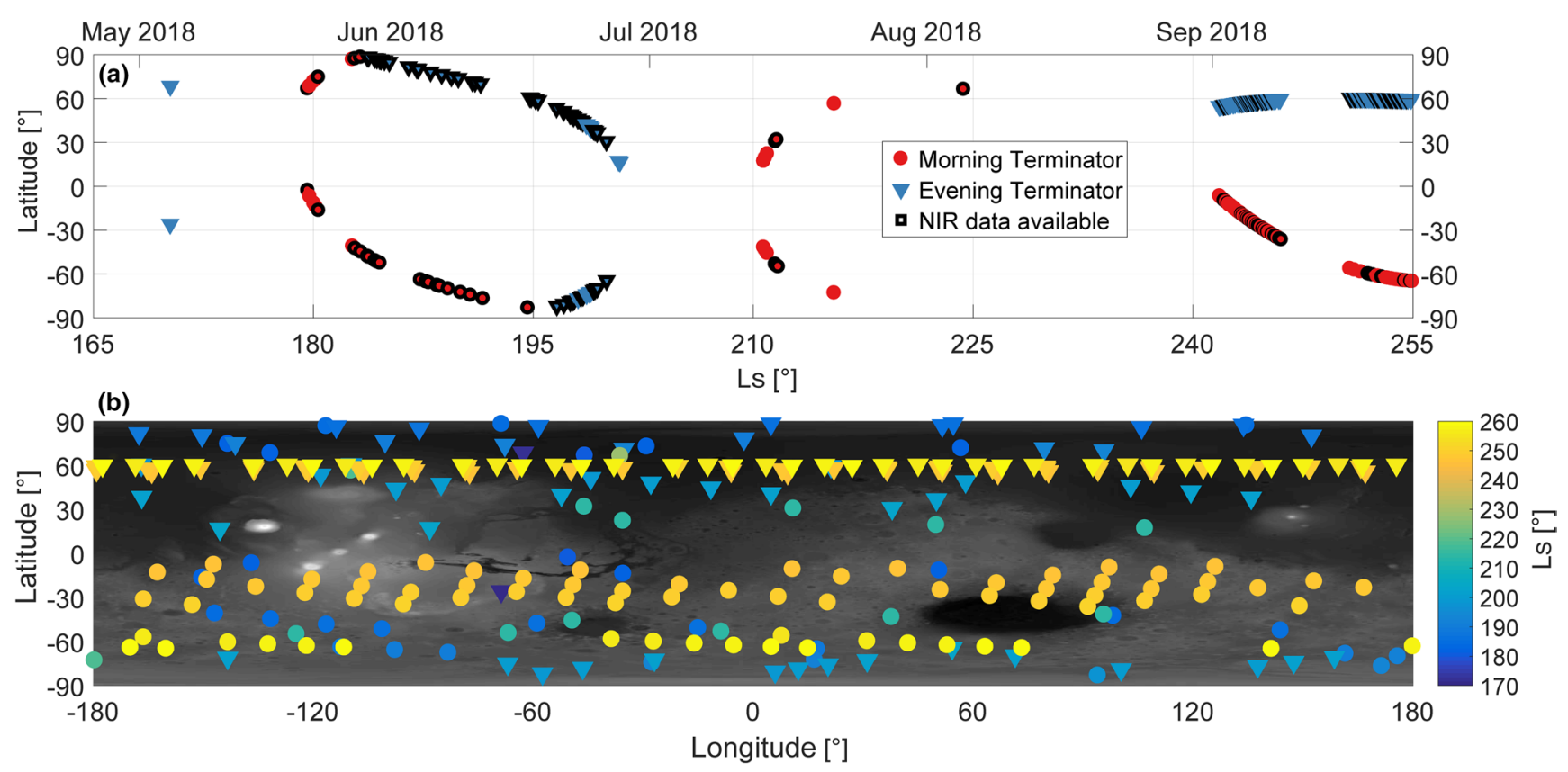

Figure 1. (a) Temporal and latitudinal distribution of Atmospheric Chemistry Suite observations from orbit \#1990 (5 May 2018 ) to orbit \#3706 (22 September 2018). Red circles and blue triangles represent thermal infrared observations made at the morning and at the evening terminators, respectively. Observations with near infrared data available are shown with black outline. (b) Latitudinal-longitudinal map of observations with the solar longitude given by the color code.

During the period of interest, $36 \%$ of the observations were made at high latitudes ( $\mid$ latitude $\geq 60^{\circ}$ ), $45 \%$ at middle latitudes $\left(30^{\circ} \leq \mid\right.$ latitude $\left.\leq 60^{\circ}\right)$, and only $19 \%$ at low latitudes (llatitudel $\left.\leq 30^{\circ}\right)$. During this time, the majority of observations at the morning terminator were carried out in the southern hemisphere (132 occurrences or $90 \%)$. In contrast, observations at the evening terminator occurred mostly in the northern hemisphere (103 or $87 \%)$.

\section{Retrieval of Vertical Profiles}

\subsection{Transmission}

The procedure to obtain transmittances from the TIRVIM data set is straightforward. The reference spectrum $I_{0}(\lambda)$ for an occultation is calculated from averaging a large number of spectra measured when observing the Sun out of the atmosphere, which is between 130 and $250 \mathrm{~km}$ of altitude. The number of averaged spectra equals 200-600 for TIRVIM and 30-100 for NIR. Inside the atmosphere, the solar irradiance $I(\lambda)$ is attenuated by aerosols and gases integrated over the line-of-sight (LOS). The ratio of this flux to the reference defines a spectrum of atmospheric transmission at a target altitude: $\operatorname{Tr}(\lambda)=I(\lambda) / I_{0}(\lambda)$. Figure 2 shows TIRVIM transmission spectra recorded during an ingress occultation observed at orbit \#2578.

As mentioned above, for TIRVIM we choose wavenumbers outside of strong gas absorption bands, which means that extinction can be calculated directly from transmission $\operatorname{Tr}(\lambda)$. For NIR, this is true only for orders 78 and 90. For orders 49, 56, and 101, the continuum transmission was estimated as a by-product of $\mathrm{CO}_{2}, \mathrm{H}_{2} \mathrm{O}$, and $\mathrm{O}_{2}$ abundances retrieval, respectively, as described by Fedorova et al. (2020).

\subsection{Slant Optical Depth and Extinction}

Once we have calculated the transmission, the slant optical depth is deduced from the Beer-Lambert law as $\tau(\lambda)=-\ln (\operatorname{Tr}(\lambda))$. Corresponding uncertainty $\delta_{\tau}$ is calculated using the propagation of error relationship $\delta_{\tau}$ $=\delta_{\mathrm{Tr}} / \mathrm{Tr}$, where $\delta_{\mathrm{Tr}}$ is the transmission uncertainty. 


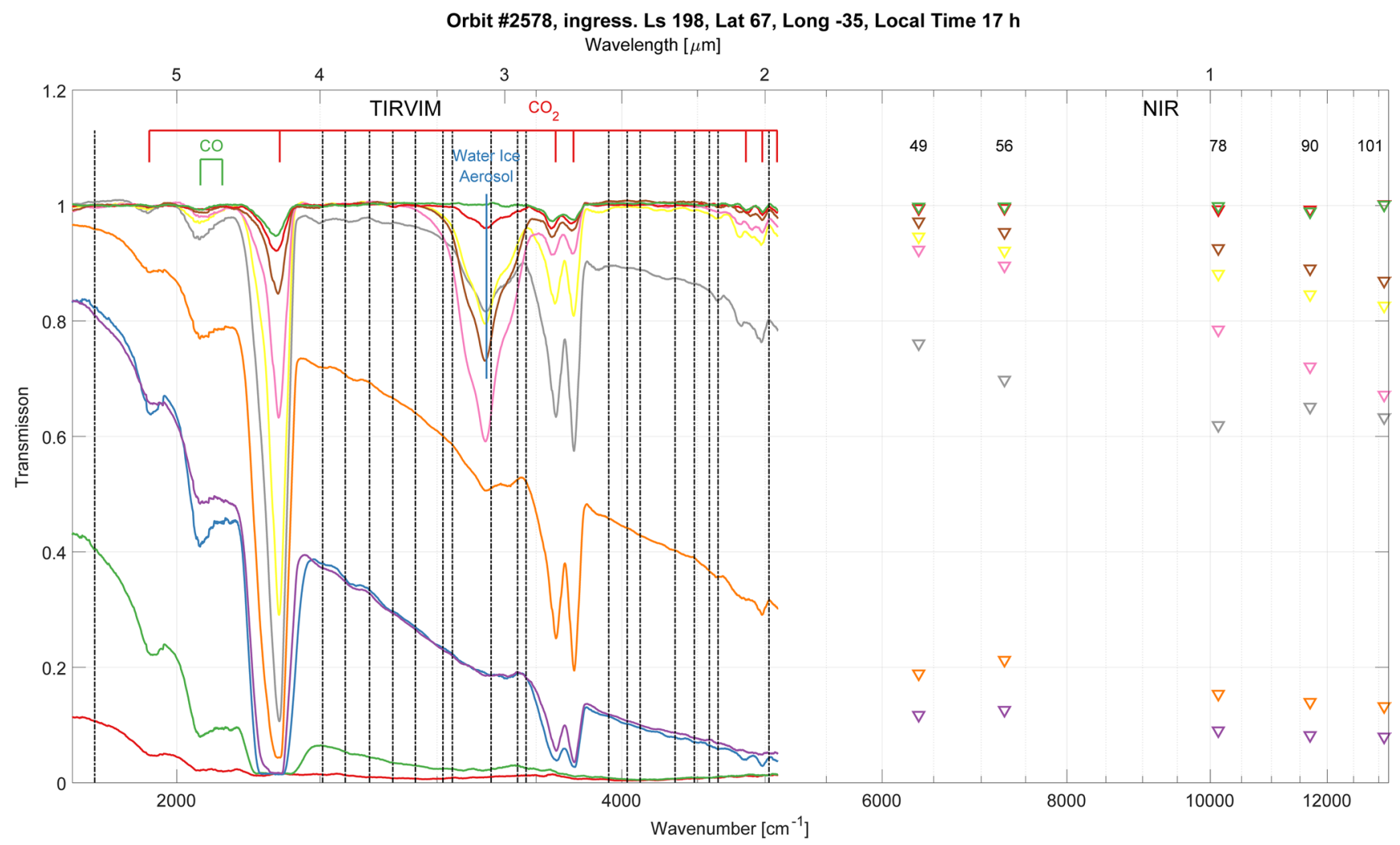

Figure 2. Transmission spectra recorded during \#2578 ingress occultation. Spectra at different altitudes are shown in different colors. Black vertical lines indicate 19 thermal infrared wavenumbers, used for the aerosol properties retrieval. $\mathrm{CO}$ and $\mathrm{CO}_{2}$ gaseous absorption bands, and the center of the characteristic water ice absorption band, are also indicated. Triangles indicate near infrared spectra.

The procedure for the retrieval of extinction profiles from slant optical depth is standard for solar occultation measurements (Fedorova et al., 2014, 2009; Korablev et al., 1993; Luginin et al., 2016; Määttänen et al., 2013) and is based on the "onion peeling" method (Rodgers, 2000). Extinction coefficient $k_{i}$ at the $i$-th layer is $k_{i}=\left(\tau_{i}-\sum_{j=i+1}^{j=N} k_{j} K_{i j}\right) / K_{i i}$, where $\tau_{i}$ is the slant optical depth for the $i$-th layer, $K_{i j}$ is the part of the geometric length of the $i$-th LOS traversed by the light in the $j$-th layer, $N$ is the number of the highest layer. $K_{i j}$ is calculated as $K_{i j}=2 \cdot\left(\sqrt{R_{j+1}^{2}-R_{i}^{2}}-\sqrt{R_{j}^{2}-R_{i}^{2}}\right)$, where $R_{j}$ is the distance from the center of Mars to the bottom of the $j$-th layer. The extinction uncertainty at the $i$-th layer $\delta_{k i}$ is calculated as $\delta_{k i}^{2}=\left(\delta^{2}{ }_{i}+\sum_{j=i+1}^{j=N} \delta_{k j}^{2} K_{i j}^{2}\right) / K_{i i}^{2}$, where $\delta_{\tau i}$ is the uncertainty of slant optical depth at the $i$-th layer. The smallest detectable extinction is determined by SNR and equals to $\sim 10^{-5} \mathrm{~km}^{-1}$ in most cases yet depends on wavelength. Figure 3 shows transmission, slant optical depth, and extinction profiles from TIRVIM and NIR recorded during \#2578 ingress occultation.

\subsection{Direct Modeling of Extinction}

The aerosol extinction is modeled according to the classical Mie theory. To compute light scattering by polydisperse spherical particles using the Lorenz-Mie theory, we apply the code by Mishchenko et al. (1999) (https://www.giss.nasa.gov/staff/mmishchenko/Lorenz-Mie.html). As a result, we obtain extinction cross-section $\sigma$ integrated over the whole ensemble of particles defined by their size distribution $n(r)$ and refractive index $m$ :

$$
\sigma(\lambda, m)=\int \pi r^{2} Q(\lambda, r, m) n(r) d r
$$

where $Q$ is the efficiency factor of extinction of a particle with size $r$ and refractive index $m$ at a wavelength $\lambda$. 


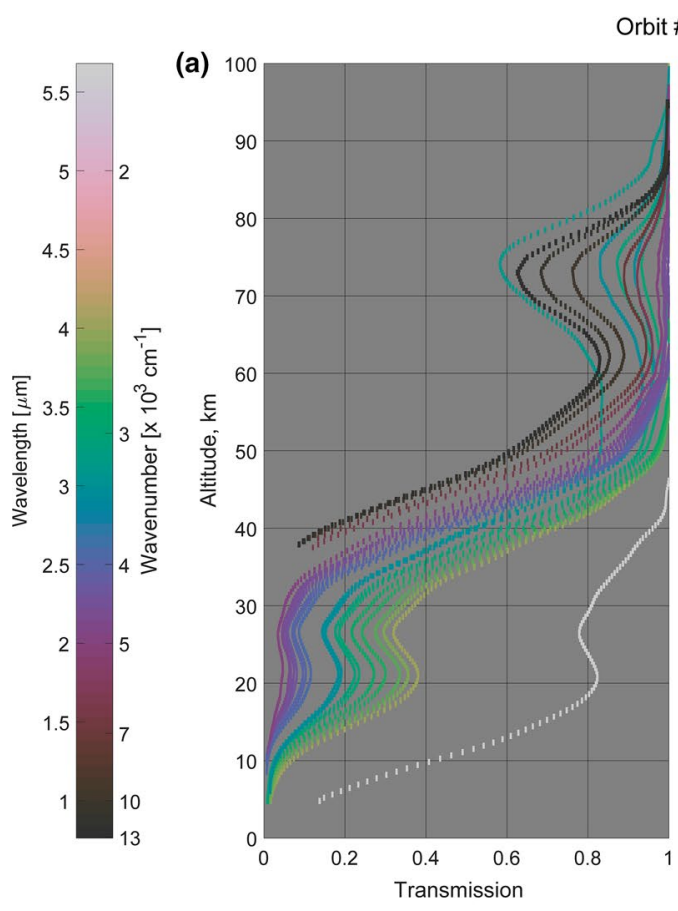

Orbit \#2578, ingress, Ls 198, Lat 48, Long -28 , Local Time $17 \mathrm{~h}$
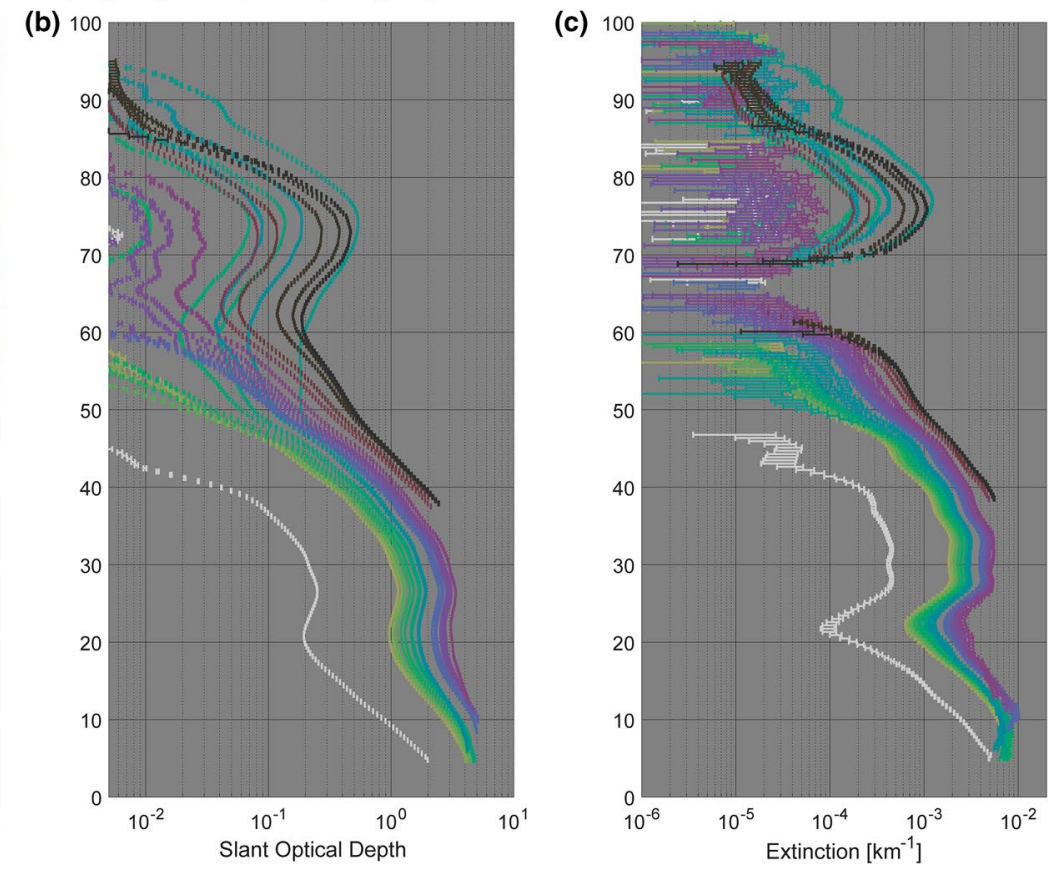

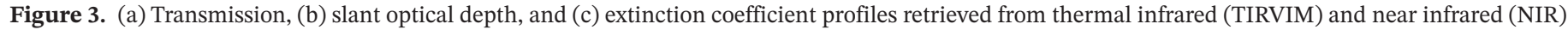

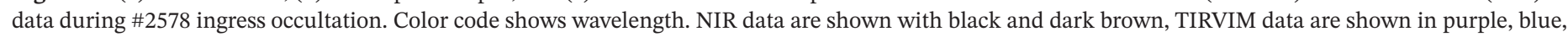
green, yellow, and white. Error bars correspond to 1- $\sigma$ uncertainty level.

Real and imaginary parts of water ice refractive index strongly depend on the temperature (Figure 4). We have used temperature profiles retrieved from the order 49 of NIR spectra, containing the $\mathrm{CO}_{2}$ absorption band at $1.57 \mu \mathrm{m}$, which provides temperature thanks to hydrostatic equilibrium and the temperature dependence of rotational lines (Fedorova et al., 2020). For the TIRVIM individual occultations, we have used temperature predictions from the Mars Climate Database (Millour et al., 2018).

For direct modeling of $\sigma$, we adopt refractive indices from Wolff et al. (2009) for dust aerosols and from Warren and Brandt (2008) and Clapp et al. (1995) for water ice aerosols, hereinafter referred to as W09, WB08, and C95, respectively. W09 estimates the refraction index of Martian dust from Compact Reconnaissance Imaging Spectrometer for Mars (CRISM) spectra onboard MRO (Murchie et al., 2007). WB08 and C95 are compilations of laboratory data on water ice refractive index, from UV to radio waves at $266 \mathrm{~K}$ (WB08), and for the $800-4,000 \mathrm{~cm}^{-1}(2.5-12.5 \mu \mathrm{m})$ spectral range at temperatures from 130 to $210 \mathrm{~K}$, every $10 \mathrm{~K}$ (C95). The imaginary part of the refractive index from C95 significantly fluctuates in the spectral region 3,600$4,000 \mathrm{~cm}^{-1}$. These data were disregarded. The optical constants from W09, WB08, and C95 in our spectral range are shown in Figure 4.

In C95, there are no data on the water ice refractive index in the 4,000-13,000 $\mathrm{cm}^{-1}$ spectral range for $T<$ $266 \mathrm{~K}$, therefore, we use the real part of the refractive index from WB08. We also scale the imaginary part from WB08 to the appropriate temperature using a gradient of $0.6 \% \mathrm{~K}^{-1}$, as advised in WB08. For $T<130 \mathrm{~K}$ and $T>266 \mathrm{~K}$, we use data from C95 and WB08, respectively, with the same approach. For $130 \mathrm{~K}<T<266$ $\mathrm{K}$, we use linear interpolation of the real part and linear interpolation of the logarithm of the imaginary part between WB08 and C95 data. Table 1 summarizes the adopted refractive indices of water ice.

For most of the widely used size distributions, single-scattering properties of spherical particles coincide if their effective radii $r_{\text {eff }}$ and effective variances $v_{\text {eff }}$ are the same (Hansen \& Travis, 1974). To describe the particle size distribution of aerosols, we use log-normal distribution $n(r)=\frac{1}{\sqrt{2 \pi} \sigma_{g} r} \exp \left(-\left(\ln r-\ln r_{g}\right)^{2} / 2 \ln ^{2} \sigma_{g}\right)$, 

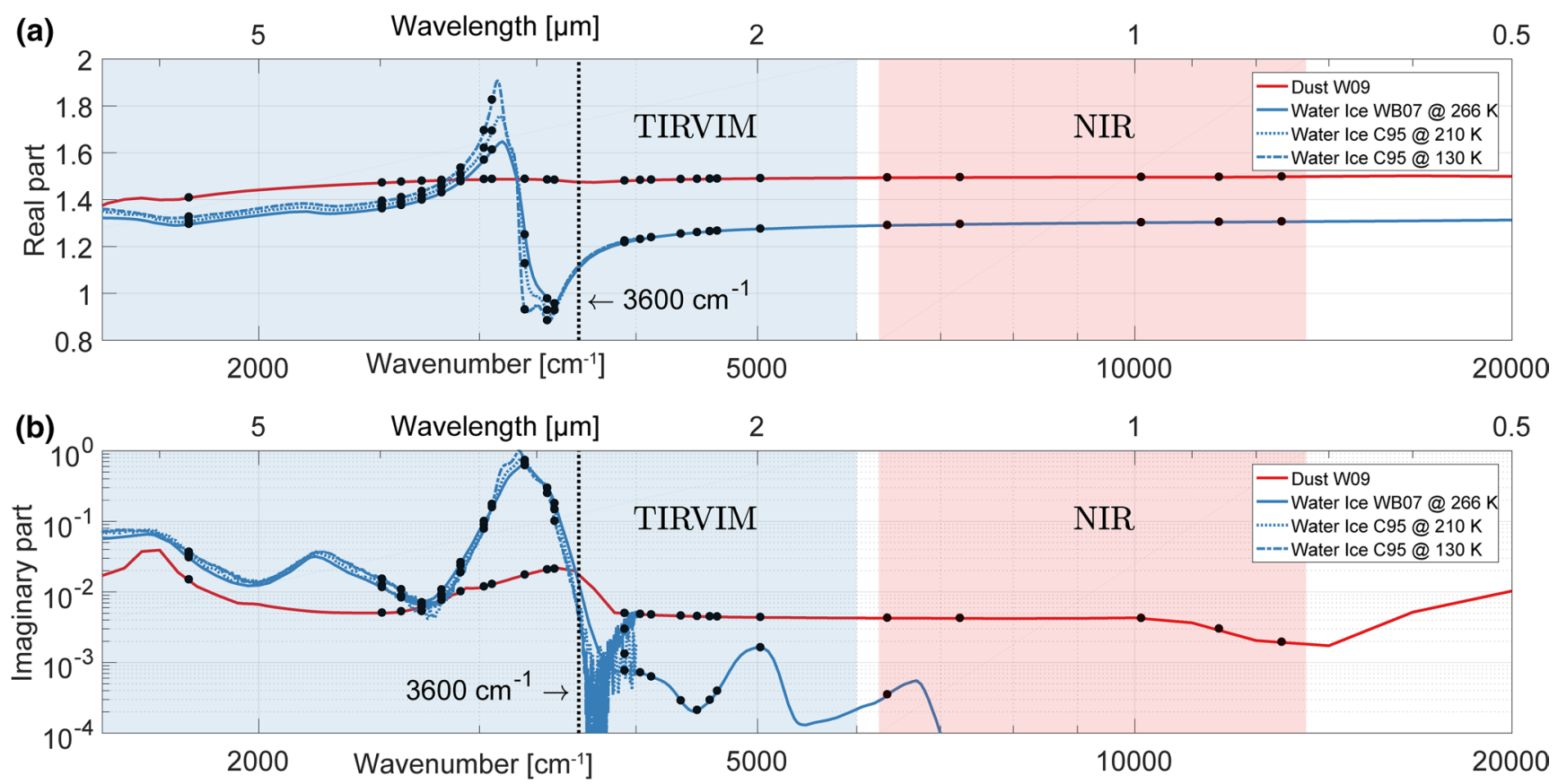

Figure 4. (a) Real and (b) imaginary parts of refractive index for dust from Wolff et al. (2009) (red curve) and for water ice from Warren and Brandt (2008) (solid blue curve) and Clapp et al. (1995) at 130 and $210 \mathrm{~K}$ (dotted and dashed blue curves). Blue and red areas mark thermal infrared (TIRVIM) and near infrared (NIR) spectral regions. Solid black circles indicate TIRVIM and NIR wavenumbers.

following Fedorova et al. (2014) and Montmessin et al. (2002). Parameters $r_{g}$ and $\sigma_{g}$ are directly connected to $r_{\text {eff }}$ and $v_{\text {eff }}$ as $r_{\text {eff }}=r_{g} \exp \left(2.5 \ln ^{2} \sigma_{g}\right), v_{\text {eff }}=\exp \left(\ln ^{2} \sigma_{g}\right)-1$. In this study, $v_{\text {eff }}$ runs over a range 0.1-0.6 with a 0.1 step.

We have computed look-up tables of $\sigma$ for mineral dust and water ice in the range $0.1-10 \mu \mathrm{m}$ with $0.1 \mu \mathrm{m}$ step for $r_{\text {eff }}$ and in the range 0.1-0.6 with 0.1 for $v_{\text {eff }}$ at all wavelengths chosen for aerosol retrievals. For water ice, the variation with temperature is also accounted for, with values distributed in the range 100-270 K with $5 \mathrm{~K}$ step. Extinction coefficient $k$ is readily calculated from $\sigma$ and the total number of particles per unit volume $N$ (number density) as $k(\lambda)=N \sigma(\lambda)$.

We have conducted a sensitivity study of TIRVIM and NIR channels to the dust and water ice particle size (see Data sets S1-S3 and Figures S1-S4 in the Supporting Information). The retrieval boundaries are 0.1

Table 1

Adopted Refractive Indices of Water Ice

\begin{tabular}{|c|c|c|c|c|}
\hline \multirow[b]{2}{*}{ Spectral range } & \multicolumn{4}{|c|}{ Temperature (K) } \\
\hline & $T \leq 130$ & $130<T \leq 210$ & $210<T \leq 266$ & $T>266$ \\
\hline \multicolumn{5}{|c|}{ Real part } \\
\hline $0.7-2.5 \mu \mathrm{m}\left(3,600-14,000 \mathrm{~cm}^{-1}\right)$ & WB08 & WB08 & WB08 & WB08 \\
\hline $2.5-6 \mu \mathrm{m}\left(1,700-3,600 \mathrm{~cm}^{-1}\right)$ & $\mathrm{C} 95$ & Linear interpolation between C95 & Linear interpolation between C95 and WB08 & WB08 \\
\hline \multicolumn{5}{|c|}{ Imaginary part } \\
\hline $0.7-2.5 \mu \mathrm{m}\left(3,600-14,000 \mathrm{~cm}^{-1}\right)$ & Scaled WB08 ${ }^{\mathrm{a}}$ & Scaled WB08 ${ }^{\mathrm{a}}$ & Scaled WB08 ${ }^{\mathrm{a}}$ & Scaled WB08 ${ }^{\mathrm{a}}$ \\
\hline $2.5-6 \mu \mathrm{m}\left(1,700-3,600 \mathrm{~cm}^{-1}\right)$ & Scaled C95 ${ }^{\mathrm{a}}$ & Log-interpolation between C95 & Log-interpolation between WB08 and C95 & Scaled WB08 ${ }^{\mathrm{a}}$ \\
\hline
\end{tabular}

Abbreviations: C95, Clapp et al. (1995); WB08, Warren and Brandt (2008).

${ }^{\mathrm{a}}$ Imaginary part scaled to appropriate temperature using $0.6 \% \mathrm{~K}^{-1}$ gradient, as advised in WB08. 
$\mu \mathrm{m} \leq r_{\text {eff }} \leq 5 \mu \mathrm{m}$ for dust and $0.1 \mu \mathrm{m} \leq r_{\text {eff }} \leq 6 \mu \mathrm{m}$ for water ice. To distinguish between dust particles with $r_{\text {eff }}=4 \mu \mathrm{m}$ and $r_{\text {eff }}=5 \mu \mathrm{m}, 5 \%$ relative accuracy is required. In the case of water ice, we need $\sim 6 \%$ relative accuracy to distinguish between $r_{\text {eff }}=5 \mu \mathrm{m}$ and $r_{\text {eff }}=6 \mu \mathrm{m}$.

\subsection{Effective Radius, Number Density, and Mass Loading}

The procedure is substantially the same as the one used for aerosol properties retrieval in Fedorova et al. (2014) and Luginin et al. (2016). To retrieve effective radius, number density, and mass loading profiles, we compose an auxiliary quantity $x(\lambda)=k(\lambda) / k\left(\lambda_{0}\right)$, which is used for fitting the model to the experimental data. $\lambda_{0}$ is chosen independently in each individual case and corresponds to the wavelength with the lowest uncertainties to minimize the $\chi$ uncertainty $\delta_{\varkappa}$, which is calculated using the propagation of error relationship.

As the composition of aerosols is a priori unknown, the retrieval algorithm is split into several steps:

1. We assume a unimodal distribution of aerosol consisting of either dust or water ice and apply an exhaustive search through the tabulated data that minimizes a merit function $\chi^{2}=\frac{1}{M-p} \sum_{i=1}^{M} \frac{\left(\varkappa_{i}-\varkappa_{i}^{\bmod }\right)^{2}}{\delta_{2 i}^{2}}$, where the subscript $i$ denotes wavelength from 1 to $M, p$ is the number of free parameters, and $\varkappa_{i}^{\bmod }\left(\lambda_{i}\right)=\frac{k^{\bmod }\left(\lambda_{i}\right)}{k^{\bmod }\left(\lambda_{0}\right)}=\frac{\sigma^{\bmod }\left(\lambda_{i}\right)}{\sigma^{\bmod }\left(\lambda_{0}\right)}$ is a modeled $\varkappa_{i}$. This gives values of $r_{\text {eff }}^{0}$ and $v_{\text {eff }}^{0}$ that are used as a first guess for the Levenberg-Marquardt fitting procedure with a single free parameter $r_{\text {eff. }}$ During this fit, effective variance is not altered and equals $v_{\text {eff }}=v_{\text {eff }}^{0}$. The result is the best fit with $\chi^{2}=\chi_{\min }^{2}$ and $r_{\text {eff }}^{\text {fit }}$ and $v_{\text {eff }}^{0}$ for each type of aerosol. The fit is considered satisfying if $\chi_{\min }^{2} \leq 1$. If the fit is satisfying only for one type of aerosol, we proceed to step 3; if it is satisfying for both types of aerosol, such measurement is disregarded; if no fit is satisfying, we proceed to step 2.

2. We assume the simultaneous presence of both types of aerosol, forming a bimodal lognormal distribution. In this case, extinction coefficient is composed of two components $k(\lambda)=N_{1} \sigma_{1}(\lambda)+N_{2} \sigma_{2}(\lambda)=N_{1}\left(\sigma_{1}(\lambda)+\gamma \sigma_{2}(\lambda)\right)$, where $\sigma_{i}(\lambda), i=1,2$ is defined in Section 3.3, and $\gamma=\frac{N_{2}}{N_{1}}$ is the number densities ratio of two modes. Here, $\varkappa_{i}^{\bmod }\left(\lambda_{i}\right)=\frac{\sigma_{1}\left(\lambda_{i}\right)+\gamma \sigma_{2}\left(\lambda_{i}\right)}{\sigma_{1}\left(\lambda_{0}\right)+\gamma \sigma_{2}\left(\lambda_{0}\right)}$. Again, we apply an exhaustive search and find first guess values for the fitting procedure $r_{\mathrm{eff}, 1}^{0}, v_{\mathrm{eff}, 1}^{0}, r_{\mathrm{eff}, 2}^{0}, v_{\mathrm{eff}, 2}^{0}$, and $\gamma^{0}$. We then apply the fitting procedure with constant effective variances $v_{\mathrm{eff}, 1}=v_{\mathrm{eff}, 1}^{0}$, and $v_{\mathrm{eff}, 2}^{0}$, and three free parameters: $r_{\mathrm{eff}, 1}, r_{\mathrm{eff}, 2}$, and $\gamma$. The fit is considered satisfying if $\chi^{2} \leq \min \left(\frac{\chi_{\min }^{2}}{2}, 5\right)$. These values were determined empirically.

Uncertainties of the free parameters are calculated from diagonal elements of the covariance matrix. Uncertainties of effective variance(s) are discussed in Data set S4 of Supporting Information. Example fits for different cases of aerosol composition are shown in Figure 5.

3. Once a satisfying fit is found, and all parameters are retrieved, the corresponding number density is calculated as $N=\frac{1}{M} \sum_{i=1}^{M} k\left(\lambda_{i}\right) / \sigma\left(\lambda_{i}\right)$. In the bimodal case, number densities of mode 1 and mode 2 are calculated as $\mathrm{N}$ and $\gamma \mathrm{N}$, respectively.

Number density uncertainty $\delta_{N}$ for the unimodal case and for mode 1 in the bimodal case is estimated as $\delta_{N}^{2}=\frac{1}{M-1} \sum_{i=1}^{M} \delta_{k}^{2}\left(\lambda_{i}\right) / \sigma^{2}\left(\lambda_{i}\right)+\frac{1}{M-1} \sum_{i=1}^{M}\left(N-k\left(\lambda_{i}\right) / \sigma\left(\lambda_{i}\right)\right)^{2}$. To get $\delta_{N}$ for mode $2, \delta^{2} N^{2}$ should be added to the previous equation.

Resulting number density profiles of particles with known effective radii are recomputed into mass loading profiles as $m=\frac{4}{3} \pi r_{\text {eff }}^{3} N \rho$, where $\rho$ is assumed to be $0.9 \mathrm{~g} \mathrm{~cm}^{-3}$ for the ice particles and $2.5 \mathrm{~g} \mathrm{~cm}^{-3}$ for the dust particles. 
(a)

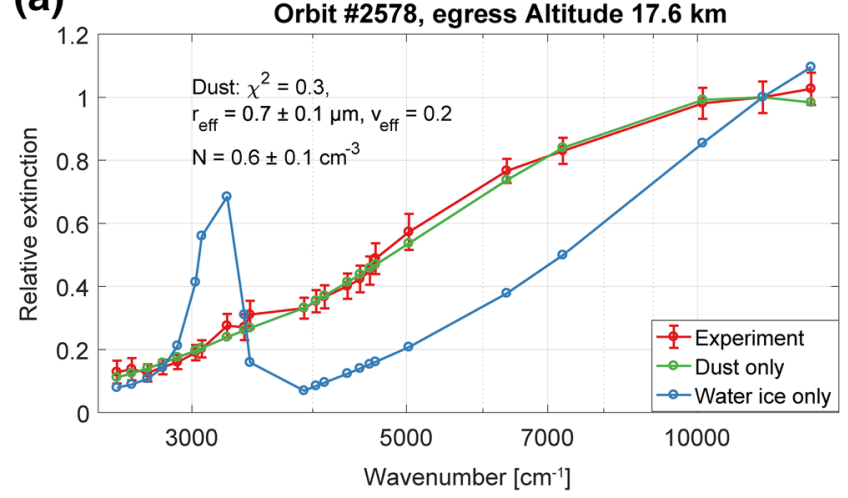

(c)

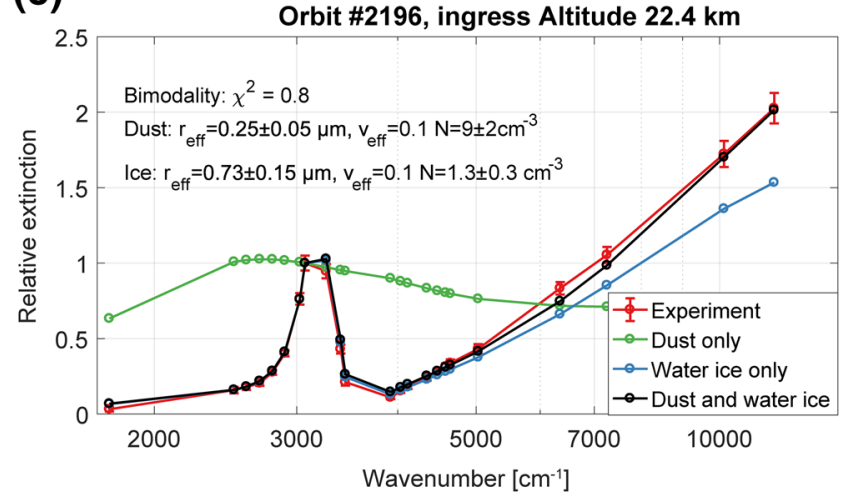

(b)

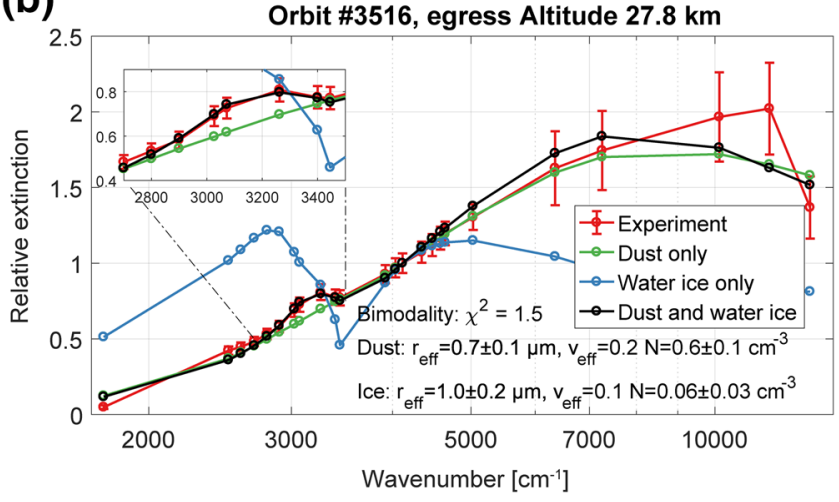

(d)

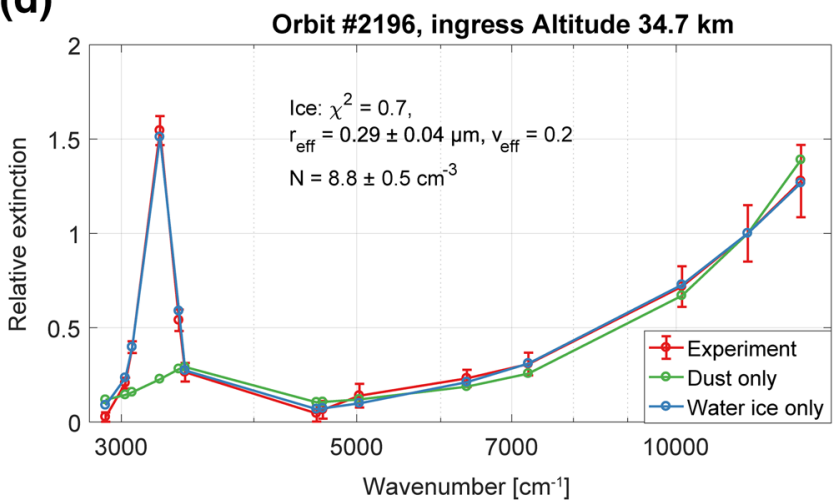

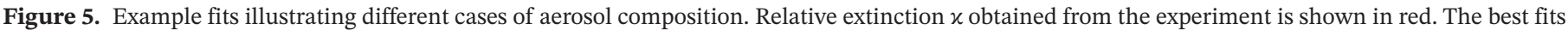

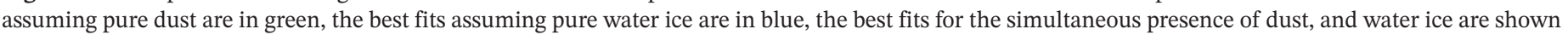

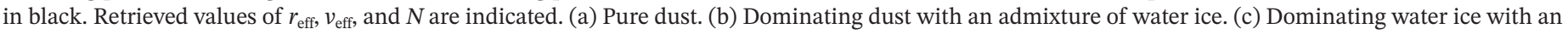
admixture of dust. (d) Pure water ice. Error bars correspond to $1-\sigma$ uncertainty level.

Some occultations featured aerosol detached layer(s) (DLs). A DL is identified as an inversion in the mass loading profile of dust or water ice (very rarely inversion of both types of aerosols is detected at the same altitude) or as a layer separated by $>10 \mathrm{~km}$ from other aerosols located below. For examples of DLs containing water ice aerosol particles, see Data set S5 and Figures S6-S8 in the Supporting Information.

In Figure 6, we show a sequence of data processing from transmission Tr through extinction $k$ to mass loading $m$ as well as retrieved profiles of effective radius $r_{\text {eff }}$, effective variance $v_{\text {eff, }}$, and number density $N$ for an example occultation \#2199 ingress, acquired on 22 May $\left(L_{S}=179.7^{\circ}, 68^{\circ} \mathrm{N}, 228^{\circ} \mathrm{E}\right)$. This occultation featured several DLs (panel c of Figure 6):

1. Inversions in the altitude range $6-17 \mathrm{~km}$, in both dust and water ice mass loading profiles (although altitudes of the inversion points are not the same).

2. A DL of dust at altitudes $20-25 \mathrm{~km}$.

\subsection{Data Filtering and Cut-Off Values}

The best SNR of the processed transmissions is achieved near the middle altitude of the profile, where $\operatorname{Tr} \approx$ 0.5. In the upper part the extinction is confidently retrieved when 1-Tr exceeds noise. The lower boundary of the profiles is variable and reflects the overall amount of aerosols suspended in the atmosphere. It can be estimated as $\operatorname{Tr}>1$ /SNR. As discussed below, the best conditions for aerosol retrievals are at high latitudes; and the presence of a GDS significantly increases the lowest sounded altitude. 
Orbit \#2199, ingress, Ls 179.7, Lat 68, Long -132, Local Time $6 \mathrm{~h}$

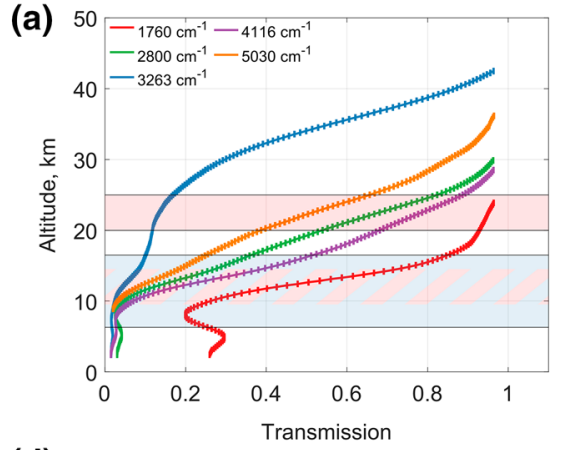

(d)

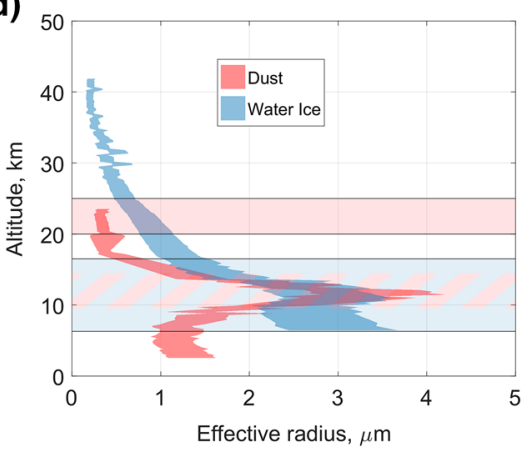

(b) 50

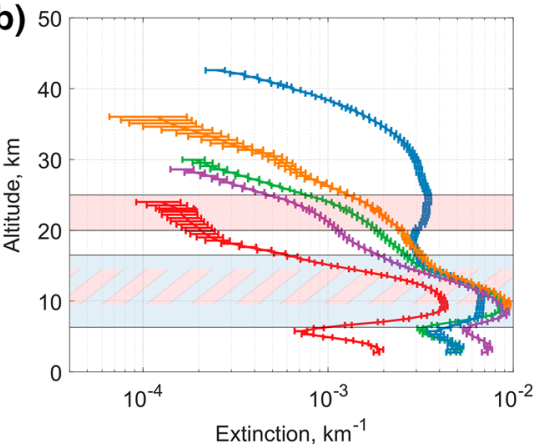

(e)

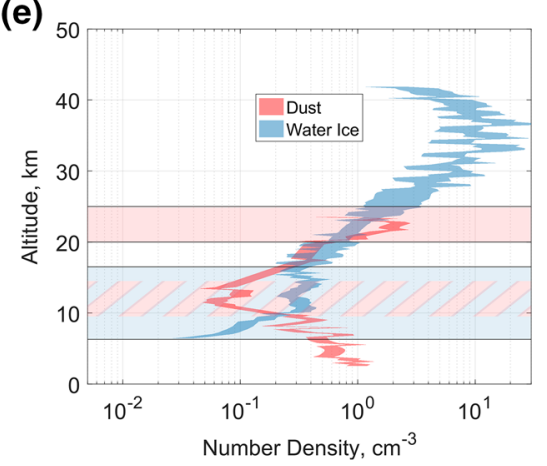

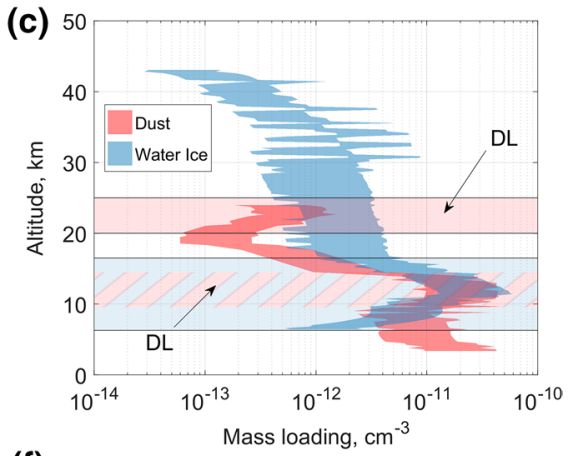

(f)

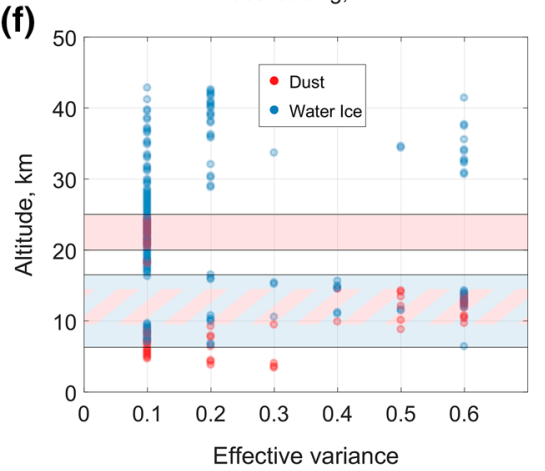

Figure 6. Vertical profiles of (a) transmission, (b) extinction, (c) mass loading, (d) effective radius, (e) number density, and (f) effective variance, retrieved from occultation \#2199, ingress. Dust and water ice particles are shown as red and blue areas. Detached layers, identified as inversions in the mass loading profile, are detected at altitudes 6-17 km and 20-25 km. The error bars or shaded regions in the profiles correspond to 1- $\sigma$ uncertainty level.

In order to remove low-signal observations and to reduce the amount of untrustworthy data, we have applied data filtering procedures throughout the data processing sequence. On each processing step, we use a $2-\sigma$ cut-off value, that is, spectra with $S \leq 2 \times \sigma_{S}$ are disregarded, where $S$ represents the row signal from the detector $I$, transmission Tr, slant optical depth $\tau$, extinction $k$, and relative extinction $\chi$. This procedure was repeated at every processing step as each operation increases the relative uncertainty. Additionally, we remove spectra for which transmission is close to unity $(1-\operatorname{Tr}) \leq 2 \times \sigma_{\mathrm{Tr}}$. Also, all the points of the profile for which the goodness of the fit is not satisfied in step 1 or 2 (see Section 3.4) are excluded.

\section{Results}

\subsection{Evolution of Dust and Water Ice during the Global Dust Storm}

We have processed all available occultations made from May to October 2018 (see Figure 1). Figure 7 shows the evolution of dust and water ice mass loading during this period for the two hemispheres. The first two TIRVIM measurements were made on 5 May $\left(L_{S}=170^{\circ}\right)$ and were systematic after 21 May $\left(L_{S}=180^{\circ}\right)$. The period before the GDS (before intense dust lifting was observed by ACS) lasted until 18 June in the northern hemisphere $\left(L_{S}=195.3^{\circ}, 59^{\circ} \mathrm{N}, 267^{\circ} \mathrm{E}\right)$ and until 22 June in the southern hemisphere $\left(L_{S}=198.1^{\circ}, 77^{\circ} \mathrm{S}\right.$, $138^{\circ} \mathrm{E}$ ). During this period, at high latitudes in both hemispheres, dust was observed at $0-30 \mathrm{~km}$, reaching $50 \mathrm{~km}$ near the equator (Figure 7, panels $\mathrm{c}$ and d). Water ice was detected at altitudes $0-40 \mathrm{~km}$ at high latitudes and up to $70 \mathrm{~km}$ near the equator. A high-altitude DL consisting of water ice was observed once on 10 June $\left(L_{S}=190.8^{\circ}, 72^{\circ} \mathrm{N}, 80^{\circ} \mathrm{E}\right)$ at $70-78 \mathrm{~km}$ (Figure 7, panel e).

The first observations of the GDS by TIRVIM and NIR solar occultations occurred on 20 June in the northern hemisphere $\left(L_{S}=196.6^{\circ}, 54^{\circ} \mathrm{N}, 242^{\circ} \mathrm{E}\right)$ and on $23 \mathrm{June}$ in the southern hemisphere $\left(L_{S}=198.3^{\circ}, 76^{\circ} \mathrm{S}\right.$, $20^{\circ} \mathrm{E}$ ). During these measurements, dust was observed $\sim 15 \mathrm{~km}$ higher compared to the most recent previous observations. The peak in the GDS activity, characterized by the highest dust elevation and a maximum 

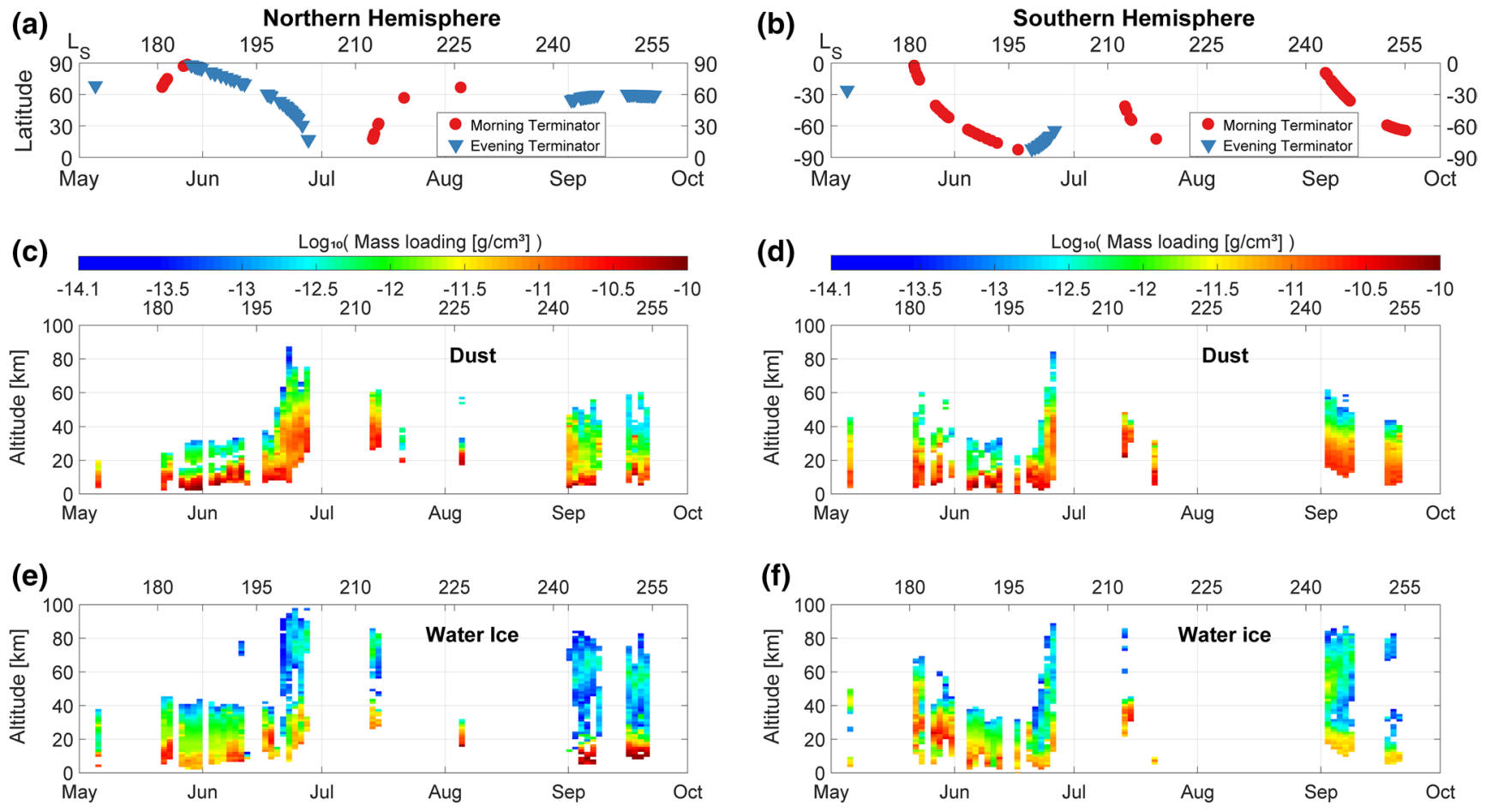

Figure 7. Evolution of dust and water ice mass loading from May till October 2018 for two hemispheres. Latitude distribution of (a, b) observations , (c, d) dust mass loading, and (e, f) water ice mass loading.

dust mass loading, was observed around $24 \mathrm{June}\left(L_{S}=199^{\circ}\right)$, where dust was observed up to $85 \mathrm{~km}$ (Figure 7, panels $\mathrm{c}$ and d). In southern polar latitudes, we saw an abrupt increase of water ice aerosols, extending from the ground up to $90 \mathrm{~km}$. In the low-to-mid latitudes of the northern hemisphere, two layers of water ice were detected: one at 0-40 km, corresponding to that seen also during the pre-GDS period, but with higher mass loading; and a detached one, located at $60-90 \mathrm{~km}$. Such DLs were often separated by $>20 \mathrm{~km}$ from other aerosols located below. Due to larger optical depth, the minimal sounding altitude raised to 20-25 km near the equator compared to $0-5 \mathrm{~km}$ before the GDS.

Starting from 13 July $\left(L_{S}=211^{\circ}\right)$, the dust top subsided $\sim 20 \mathrm{~km}$ lower, although the mass loading was approximately the same compared to the previous period. In the low-to-mid latitude regions, water ice exhibited two layers, but the detached one was located 5-10 km lower. Ingress occultation \#2844, performed on 13 July $\left(L_{S}=211^{\circ}, 41^{\circ} \mathrm{S}, 96^{\circ} \mathrm{E}\right)$, captured three thin $(1-2 \mathrm{~km})$ DLs with mass loading $\sim 10^{-13} \mathrm{~g} / \mathrm{cm}^{3}$, located at 60,74 , and $83 \mathrm{~km}$ (Figure 7, panel f). The minimum sounding altitude was $30 \mathrm{~km}$ during this period. As explained in Section 2.3, almost no occultations were made from 16 July to 31 August $\left(L_{S}=216^{\circ}-242^{\circ}\right)$ during the decay of the GDS.

Systematic observations were resumed in September and were carried out using a 2-week cadence, starting on 1 September $\left(L_{S}=242^{\circ}\right)$ and on 15 September $\left(L_{S}=251^{\circ}\right)$. At mid-to-high latitudes (llatitudel $\leq 45^{\circ}$ ), dust was observed from $5-20 \mathrm{~km}$ to $50-60 \mathrm{~km}$, while at $60^{\circ} \mathrm{S}$ dust was observed at $5-40 \mathrm{~km}$. At $60^{\circ} \mathrm{S}$, water ice was detected at 5-40 km, in some cases forming DLs at 70-80 km. At high and middle latitudes, water ice was typically located from the lowest sounded altitudes to $80 \mathrm{~km}$; DLs were also present, although less frequently. A local maximum of water ice was detected at $10^{\circ} \mathrm{S}-30^{\circ} \mathrm{S}$ at $40-60 \mathrm{~km}$.

On this basis, we can distinguish three periods in the evolution of the GDS, captured by ACS TIRVIM and NIR observations:

1. The period before the GDS $\left(L_{S}=180^{\circ}-195^{\circ}\right.$ in the northern hemisphere and $L_{S}=180^{\circ}-198^{\circ}$ in southern hemisphere), also referred to as pre-GDS period. 


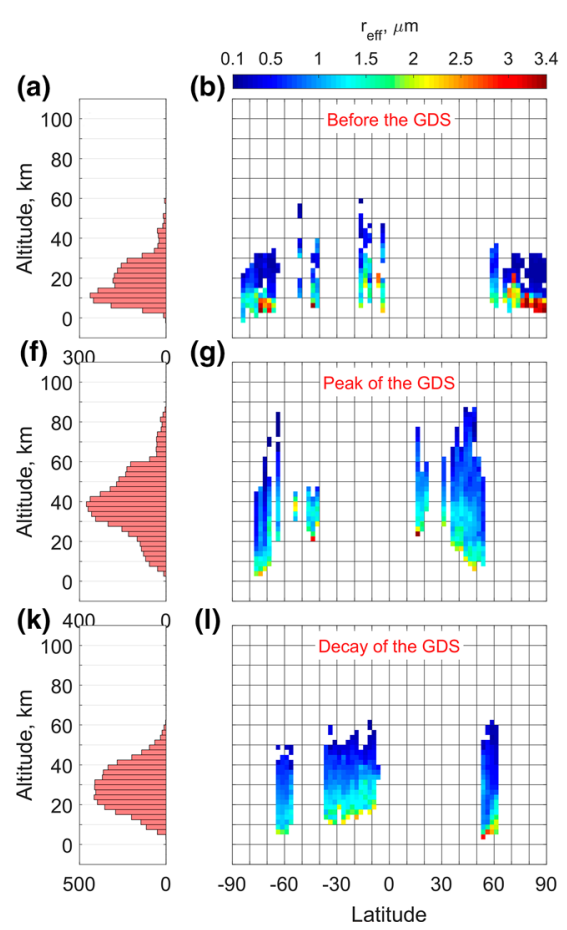

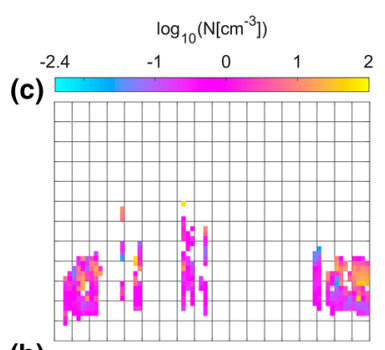

(h)

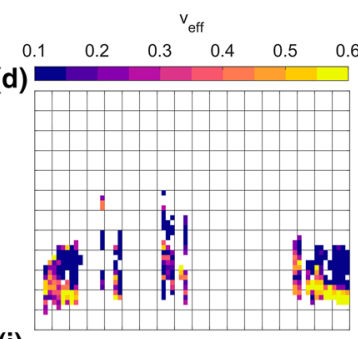

(i)

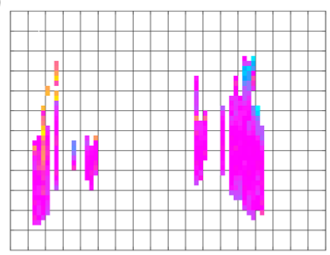

(m)

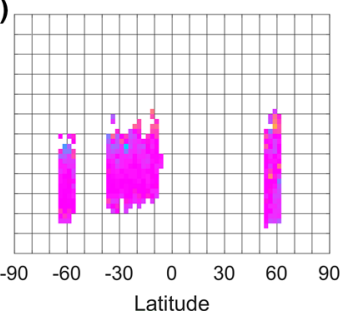

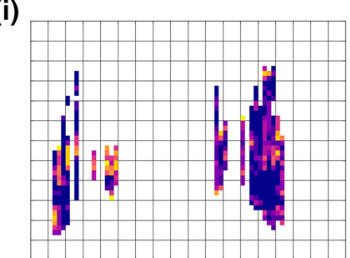

(n)

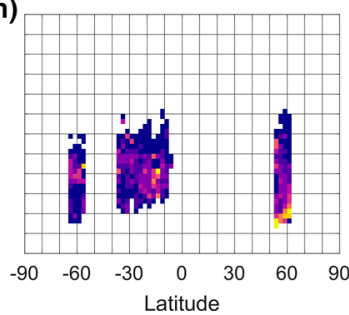

(e)

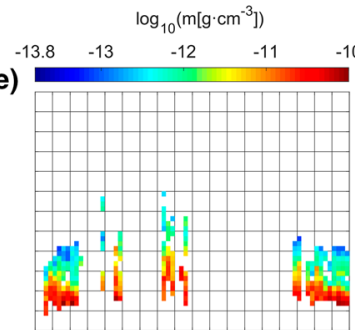

(j)

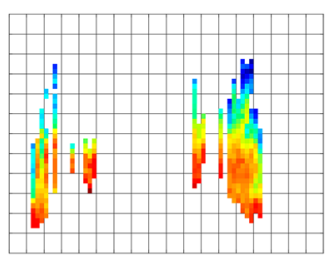

(o)

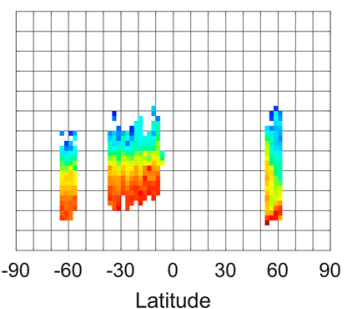

Figure 8. Altitude distribution of dust detections (left column, panels a, $\mathrm{f}, \mathrm{k}$ ), latitude-altitude cross-sections of effective radius (second column, panels $\mathrm{b}$, g, l), number density (third column, panels c, h, $\mathrm{m}$ ), effective variance (fourth column, panels d, i, n), and mass loading (fifth column, panels e, $\mathrm{j}, \mathrm{o}$ ) averaged in three $L_{S}$ bins arranged in three rows from the top to the bottom: before the GDS (panels a-e), during the onset and peak of the GDS (panels f-j), and during the decay of the GDS (panels k-o).

2. The outbreak and the peak of the GDS $\left(L_{S}=196^{\circ}-212^{\circ}\right.$ in the northern hemisphere and $L_{S}=198^{\circ}-212^{\circ}$ in the southern hemisphere), referred to as the peak of the GDS in the text.

3. The decay of the GDS $\left(L_{S}=242^{\circ}-255^{\circ}\right)$.

We will present the results of our analysis in the form of latitude-altitude cross-sections of effective radius, number density, effective variance, and mass loading for dust (Figure 8, Table 2) and water ice (Figure 9, Table 3) for the three selected $L_{S}$ bins.

\subsection{Dust Maps}

\subsubsection{Before the Global Dust Storm}

Altitude distribution of dust detection (Figure 8, panel a) showed a narrow peak at $15 \mathrm{~km}$ detaching from an otherwise thick haze extending up to $30 \mathrm{~km}$. The effective radius varied between 0.1 and $3.5 \mu \mathrm{m}$. The most massive particles $(3-3.5 \mu \mathrm{m})$ were found at $2-10 \mathrm{~km}$ at $75-90^{\circ} \mathrm{N}$ and $65^{\circ} \mathrm{S}-75^{\circ} \mathrm{S}$, while the smallest particles $(<0.5 \mu \mathrm{m})$ were present between 15 and $30 \mathrm{~km}$ at $55^{\circ} \mathrm{N}-90^{\circ} \mathrm{N}$ and $65^{\circ} \mathrm{S}-75^{\circ} \mathrm{S}$ (Figure 8, panel b). Number density varied in the range $0.04-40 \mathrm{~cm}^{-3}$ (Figure 8 , panel c).

For most effective radii values, we found an associated effective variance of 0.1-0.2 (Figure 8, panel d). For larger particles $(2.5-3.5 \mu \mathrm{m})$, the effective variance was higher, 0.5-0.6. Intermediate cases were rarely observed. Mass loading was distributed in the range $10^{-13}-10^{-10} \mathrm{~g} / \mathrm{cm}^{3}$, decreased with altitude, and, for the same altitude level, was larger at low latitudes (Figure 8, panel e).

\subsubsection{The Peak of the Global Dust Storm}

At this time, dust extended from 10 to $60 \mathrm{~km}$, with a maximum at $40 \mathrm{~km}$ (Figure 8, panel f). In a few cases, dust reached up to $85 \mathrm{~km}$. Large particles $\left(r_{\text {eff }}=2.5-3.4 \mu \mathrm{m}, N=0.1-0.4 \mathrm{~cm}^{-3}\right.$, $v_{\text {eff }}=0.5-0.6, m=2 \times 10^{-11}$ $10^{-10} \mathrm{~g} / \mathrm{cm}^{3}$ ) were observed only at the lowest sounded altitudes and very rarely, due to increased optical 
Table 2

Properties of the Dust Aerosol During the Three Phases of the GDS

\begin{tabular}{|c|c|c|c|c|c|}
\hline Latitude $\left({ }^{\circ}\right)$ & $H(\mathrm{~km})$ & $r_{\text {eff }}(\mu \mathrm{m})$ & $N\left(\mathrm{~cm}^{-3}\right)$ & $v_{\text {eff }}$ & $m\left(\mathrm{~g} / \mathrm{cm}^{3}\right)$ \\
\hline \multicolumn{6}{|c|}{ Before the GDS } \\
\hline \multicolumn{6}{|c|}{$L_{S}=180^{\circ}-195^{\circ}$ in the northern hemisphere and $L_{S}=180^{\circ}-198^{\circ}$ in the southern hemisphere } \\
\hline $75^{\circ} \mathrm{S}-85^{\circ} \mathrm{S}$ & $0-25$ & $0.1-2$ & $0.1-10$ & $0.1-0.6$ & $10^{-13}-3 \times 10^{-11}$ \\
\hline $60^{\circ} \mathrm{S}-75^{\circ} \mathrm{S}$ & $0-35$ & $0.1-3.5$ & $0.1-20$ & $0.1,0.6$ & $10^{-13}-5 \times 10^{-11}$ \\
\hline $0^{\circ} \mathrm{S}-55^{\circ} \mathrm{S}$ & $5-55$ & $0.1-2$ & $0.1-10$ & $0.1-0.2$ & $3 \times 10^{-13}-8 \times 10^{-11}$ \\
\hline $55^{\circ} \mathrm{N}-75^{\circ} \mathrm{N}$ & $5-35$ & $0.1-3$ & $0.05-10$ & $0.1-0.6^{\mathrm{a}}$ & $10^{-13}-4 \times 10^{-11}$ \\
\hline \multirow{2}{*}{$75^{\circ} \mathrm{N}-90^{\circ} \mathrm{N}$} & $5-10$ & $2.5-3.5$ & $0.05-0.2$ & 0.6 & $10^{-11}-5 \times 10^{-11}$ \\
\hline & $10-30$ & $0.1-1$ & $0.5-30$ & 0.1 & $10^{-13}-3 \times 10^{-12}$ \\
\hline \multicolumn{6}{|c|}{ The outbreak and the peak of the GDS } \\
\hline \multicolumn{6}{|c|}{$L_{S}=196^{\circ}-212^{\circ}$ in the northern hemisphere and $L_{S}=198^{\circ}-212^{\circ}$ in the southern hemisphere } \\
\hline $60^{\circ} \mathrm{S}-80^{\circ} \mathrm{S}$ & $5-85$ & $0.1-1.6$ & $0.2-3$ & $0.1-0.2$ & $3 \times 10^{-12}-3 \times 10^{-11}$ \\
\hline $40^{\circ} \mathrm{S}-55^{\circ} \mathrm{S}$ & $20-50$ & $0.8-1.8$ & $0.2-0.8$ & $0.1-0.6$ & $2 \times 10^{-12}-8 \times 10^{-11}$ \\
\hline $15^{\circ} \mathrm{N}-25^{\circ} \mathrm{N}$ & $20-80$ & $0.6-1.4$ & $0.1-1$ & $0.1-0.3$ & $10^{-12}-3 \times 10^{-11}$ \\
\hline $30^{\circ} \mathrm{N}-55^{\circ} \mathrm{N}$ & $5-90$ & $0.5-1.8$ & $0.05-1$ & $0.1-0.3$ & $3 \times 10^{-13}-3 \times 10^{-11}$ \\
\hline All of the above & Lowest sound altitudes & $2.5-3.5$ & $0.1-0.4$ & $0.5-0.6$ & $2 \times 10^{-11}-10^{-10}$ \\
\hline \multicolumn{6}{|c|}{ The decay of the GDS. $L_{S}=242^{\circ}-255^{\circ}$} \\
\hline $55^{\circ} \mathrm{S}-65^{\circ} \mathrm{S}$ & $5-50$ & $0.3-1.5$ & $0.2-1$ & $0.1-0.2$ & $3 \times 10^{-13}-2 \times 10^{-11}$ \\
\hline $10^{\circ} \mathrm{S}-40^{\circ} \mathrm{S}$ & $10-60$ & $0.2-2.2$ & $0.2-0.6$ & $0.1-0.2$ & $3 \times 10^{-13}-3 \times 10^{-11}$ \\
\hline \multirow{2}{*}{$50^{\circ} \mathrm{N}-65^{\circ} \mathrm{N}$} & $5-10$ & $1.6-2.8$ & $0.1-0.5$ & $0.4-0.6$ & $3 \times 10^{-12}-3 \times 10^{-11}$ \\
\hline & $10-60$ & $0.2-1.5$ & $0.1-1$ & $0.1-0.3$ & $2 \times 10^{-13}-3 \times 10^{-12}$ \\
\hline
\end{tabular}

Abbreviation: GDS, global dust storm.

${ }^{a} v_{\text {eff }}=0.1$ was observed in $\sim 50 \%$ of cases, other values are distributed evenly.

depth during this period (Figure 8, panel g). The size of the dust particles was typically 1-2 $\mu$ m. For most of the observations, the number density was $0.1-1 \mathrm{~cm}^{-3}$, reaching values $<0.05 \mathrm{~cm}^{-3}$ and $>3 \mathrm{~cm}^{-3}$ in a few cases (Figure 8, panel h). Effective variance was found to be 0.1 in $50 \%$ of cases, $0.2-0.3$ in $~ 40 \%$ of cases. Values $>0.3$ were observed in $\sim 10 \%$ of observations only (Figure 8, panel i). Mass loading distribution had a maximum at $10^{-11} \mathrm{~g} / \mathrm{cm}^{3}$, rapidly decreasing to $10^{-13} \mathrm{~g} / \mathrm{cm}^{3}$; values $>3 \times 10^{-11} \mathrm{~g} / \mathrm{cm}^{3}$ were found only at lowest altitudes (Figure 8, panel $\mathrm{j}$ ).

Observations made at $L_{S}=211^{\circ}-212^{\circ}, 40^{\circ} \mathrm{S}-55^{\circ} \mathrm{S}$ showed a prominent downward motion of the dust layer. Dust particles $\left(r_{\text {eff }}=0.8-1.8 \mu \mathrm{m}, N=0.2-0.8 \mathrm{~cm}^{-3}, v_{\text {eff }}=0.1-0.6\right)$ were detected at $20-50 \mathrm{~km}$. The top altitude was $10-20 \mathrm{~km}$ lower compared to the altitude top at $40-60^{\circ} \mathrm{N}$ recorded during the maximum of GDS and that was not affected by the GDS. The lowest sounded altitude was the same as in the northern hemisphere, and $10 \mathrm{~km}$ higher compared to the previous period. The mass loading was $2 \times 10^{-12}-8 \times 10^{-11} \mathrm{~g} / \mathrm{cm}^{3}, 2-3$ times greater than at $L_{S}=210^{\circ}-211^{\circ}, 15^{\circ} \mathrm{N}-25^{\circ} \mathrm{N}$ (Figure 8, panel j).

\subsubsection{The Decay of the Global Dust Storm}

During the decay of the GDS, dust extended from 5 to $50 \mathrm{~km}$, with a maximum at $27 \mathrm{~km}$ (Figure 8, panel k). The most frequently observed size of dust particles was $0.2-1.4 \mu \mathrm{m}$, with larger particles $(2-3 \mu \mathrm{m})$ detected at $5-10 \mathrm{~km}$ at $50^{\circ} \mathrm{N}-65^{\circ} \mathrm{N}$, and smaller particles $(0.1-0.2 \mu \mathrm{m})$ at $50-60 \mathrm{~km}$ (Figure 8, panel 1). Number density was distributed mostly in the range from 0.2 to $0.6 \mathrm{~cm}^{-3}$, while a few observations lay outside this range, yielding values of 0.01 and $4 \mathrm{~cm}^{-3}$ (Figure 8, panel $\mathrm{m}$ ). Effective variance was $0.1-0.2$ in $>80 \%$ of cases, with values up to $0.4-0.6$ corresponding to large particles at $5-10 \mathrm{~km}$ at $50^{\circ} \mathrm{N}-65^{\circ} \mathrm{N}$ (Figure 8, panel 

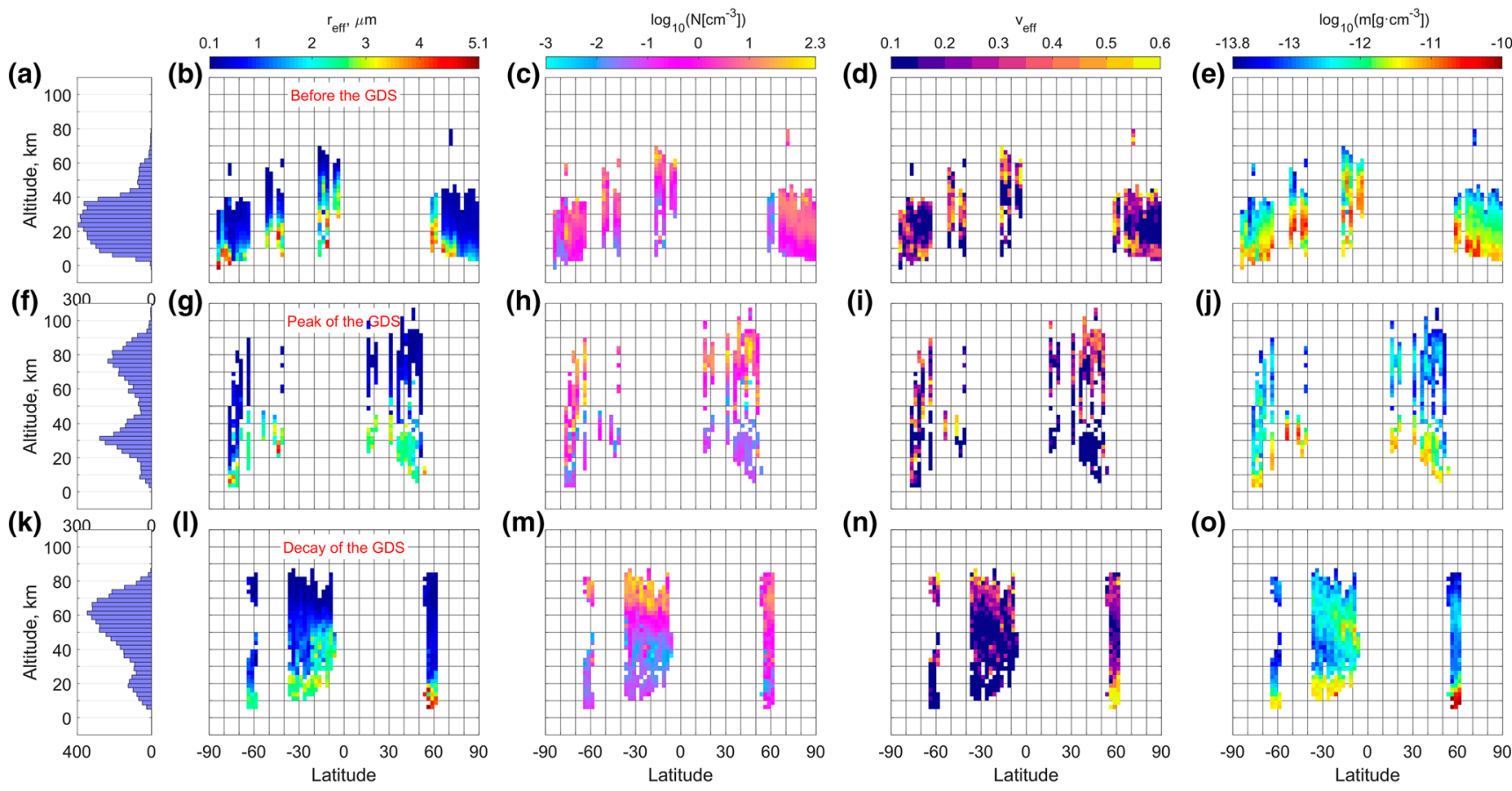

Figure 9. The same as in Figure 8 for water ice.

n). Mass loading decreased gradually from $2 \times 10^{-11} \mathrm{~g} / \mathrm{cm}^{3}$ at $5-20 \mathrm{~km}$ to $3 \times 10^{-13} \mathrm{~g} / \mathrm{cm}^{3}$ at $40-50 \mathrm{~km}$ (Figure 8, panel o).

\subsection{Water Ice Maps}

\subsubsection{Before the Global Dust Storm}

Water ice particles were observed at $0-40 \mathrm{~km}$ at the poles and up to $70 \mathrm{~km}$ near the equator in what appears to be DLs located between 30 and $70 \mathrm{~km}$. Overall, the effective radius ranged from 0.1 to $5.5 \mu \mathrm{m}$ and decreased with altitude (Figure 9, panel b). Large particles $(3.5-5.5 \mu \mathrm{m})$ were detected at almost all latitudes (except for regions $60^{\circ} \mathrm{S}-75^{\circ} \mathrm{S}$ and $\left.75^{\circ} \mathrm{N}-90^{\circ} \mathrm{N}\right)$ at the lowest sounded altitudes. Small particles $(<0.5 \mu \mathrm{m})$ were present in the upper parts of the profiles. Equatorial DLs consisted of large particles $(2-3.5 \mu \mathrm{m})$ at $30-50 \mathrm{~km}$. DLs were also detected at $77^{\circ} \mathrm{S}, 43^{\circ} \mathrm{S}$, and $72^{\circ} \mathrm{N}$ at $54-58,58-62$, and $70-78 \mathrm{~km}$, respectively, consisting of $0.1-0.2 \mu \mathrm{m}$ water ice particles with a $1-10 \mathrm{~cm}^{-3}$ number density (Figure 9, panels b and c). Overall, most of the observed number densities were within $0.04-40 \mathrm{~cm}^{-3}$.

Nearly half of observations yielded an effective variance of 0.1 , other retrieved values were distributed evenly from 0.2 to 0.6 (Figure 9, panel d). A broad distribution was characteristic of the largest particles (3-5 $\mu \mathrm{m})$, but also of particles smaller than $0.5 \mu \mathrm{m}$. Mass loading varied in the range $3 \times 10^{-14}-3 \times 10^{-11} \mathrm{~g} / \mathrm{cm}^{3}$ and was generally higher at low latitudes (Figure 9, panel e). Meanwhile, high latitudes of the northern hemisphere were densely populated with ice particles, showing a mass loading of 2-5 times higher than average.

\subsubsection{The Peak of the Global Dust Storm}

The altitude distribution of water ice aerosols (Figure 9, panel f) showed two maxima: the main layer, located at $0-50 \mathrm{~km}$, and the detached one at $50-100 \mathrm{~km}$. The main layer was composed of 1-3.5 $\mu \mathrm{m}$ particles at $30^{\circ} \mathrm{N}-55^{\circ} \mathrm{N}$ and of $0.1-4 \mu \mathrm{m}$ particles at $70-80^{\circ} \mathrm{S}$ (Figure 9, panel g), while the DL consisted of smaller particles $(0.1-1 \mu \mathrm{m})$. In the lower layer, effective variance was 0.1 in $80 \%$ of the cases, while in the DL, it was spread almost evenly from 0.1 to 0.5 (Figure 9, panel i). The mass loading in the lower layer varied from $10^{-13}$ to $10^{-11} \mathrm{~g} / \mathrm{cm}^{3}$, while in the DL it was an order of magnitude smaller (Figure 9, panel j). 
Table 3

Properties of the Water Ice Aerosol During the Three Phases of the GDS

\begin{tabular}{|c|c|c|c|c|c|}
\hline Latitude $\left(^{\circ}\right)$ & $H(\mathrm{~km})$ & $r_{\text {eff }}(\mu \mathrm{m})$ & $N\left(\mathrm{~cm}^{-3}\right)$ & $v_{\text {eff }}$ & $m\left(\mathrm{~g} / \mathrm{cm}^{3}\right)$ \\
\hline \multicolumn{6}{|c|}{ Before the GDS } \\
\hline \multicolumn{6}{|c|}{$L_{S}=180^{\circ}-195^{\circ}$ in the northern hemisphere and $L_{S}=180^{\circ}-198^{\circ}$ in the southern hemisphere } \\
\hline $75^{\circ} \mathrm{S}-85^{\circ} \mathrm{S}$ & $0-40$ & $0.1-4.5$ & $0.01-10$ & $0.1-0.6^{\mathrm{a}}$ & $3 \times 10^{-14}-10^{-11}$ \\
\hline $60^{\circ} \mathrm{S}-75^{\circ} \mathrm{S}$ & $0-40$ & $0.2-2.5$ & $0.1-10$ & $0.1-0.6^{\mathrm{a}}$ & $2 \times 10^{-13}-2 \times 10^{-11}$ \\
\hline $40^{\circ} \mathrm{S}-55^{\circ} \mathrm{S}$ & $5-60$ & $0.1-4.5$ & $0.04-40$ & $0.1-0.6^{\mathrm{a}}$ & $3 \times 10^{-14}-3 \times 10^{-11}$ \\
\hline \multirow{2}{*}{$10^{\circ} \mathrm{S}-20^{\circ} \mathrm{S}$} & $5-35$ & $1.5-4.5$ & $0.03-3$ & $0.1-0.6^{\mathrm{a}}$ & $3 \times 10^{-13}-2 \times 10^{-11}$ \\
\hline & DL: $35-70$ & $0.1-3$ & $0.04-40$ & $0.1-0.6^{\mathrm{a}}$ & $10^{-13}-10^{-11}$ \\
\hline $0^{\circ} \mathrm{S}-10^{\circ} \mathrm{S}$ & DL: $30-60$ & $0.1-3.5$ & $0.05-50$ & $0.1,0.6$ & $3 \times 10^{-12}-10^{-11}$ \\
\hline $55^{\circ} \mathrm{N}-75^{\circ} \mathrm{N}$ & $5-45$ & $0.1-4$ & $0.01-30$ & $0.1-0.6^{\mathrm{a}}$ & $8 \times 10^{-14}-5 \times 10^{-11}$ \\
\hline $75^{\circ} \mathrm{N}-90^{\circ} \mathrm{N}$ & $0-45$ & $0.2-1.5$ & $0.3-10$ & 0.1 & $8 \times 10^{-14}-8 \times 10^{-12}$ \\
\hline \multicolumn{6}{|c|}{ The outbreak and the peak of the GDS } \\
\hline \multicolumn{6}{|c|}{$L_{S}=196^{\circ}-212^{\circ}$ in the northern hemisphere and $L_{S}=198^{\circ}-212^{\circ}$ in the southern hemisphere } \\
\hline \multirow{2}{*}{$70^{\circ} \mathrm{S}-80^{\circ} \mathrm{S}$} & $0-50$ & $0.1-4$ & $0.01-40$ & $0.1-0.6^{\mathrm{a}}$ & $5 \times 10^{-13}-8 \times 10^{-12}$ \\
\hline & DL: $50-90$ & $0.1-1$ & $0.3-50$ & $0.1-0.6^{\mathrm{a}}$ & $3 \times 10^{-14}-8 \times 10^{-13}$ \\
\hline $40^{\circ} \mathrm{S}-55^{\circ} \mathrm{S}$ & $20-50$ & $1.5-4.5$ & $0.01-0.5$ & $0.1-0.2,0.5-0.6$ & $5 \times 10^{-14}-3 \times 10^{-11}$ \\
\hline \multirow{2}{*}{$15^{\circ} \mathrm{N}-25^{\circ} \mathrm{N}$} & $20-50$ & $2.5-3$ & $0.01-0.1$ & 0.1 & $5 \times 10^{-12}-10^{-11}$ \\
\hline & DL: $50-90$ & $0.1-0.7$ & $4-20$ & $0.1-0.2$ & $2 \times 10^{-13}-10^{-12}$ \\
\hline \multirow{2}{*}{$30^{\circ} \mathrm{N}-55^{\circ} \mathrm{N}$} & $5-40$ & $1-3.5$ & $0.01-0.1$ & 0.1 & $10^{-13}-8 \times 10^{-12}$ \\
\hline & DL: $40-95$ & $0.1-0.6$ & $0.2-100$ & $0.1-0.6^{\mathrm{a}}$ & $2 \times 10^{-14}-5 \times 10^{-13}$ \\
\hline \multicolumn{6}{|c|}{ The decay of the GDS. $L_{S}=242^{\circ}-255^{\circ}$} \\
\hline \multirow{2}{*}{$55^{\circ} \mathrm{S}-65^{\circ} \mathrm{S}$} & $5-40$ & $0.5-2.8$ & $0.01-1$ & 0.1 & $3 \times 10^{-14}-5 \times 10^{-12}$ \\
\hline & DL: $65-85$ & $0.1-0.7$ & $0.1-50$ & $0.1-0.6$ & $5 \times 10^{-14}-2 \times 10^{-13}$ \\
\hline \multirow{2}{*}{$10^{\circ} \mathrm{S}-40^{\circ} \mathrm{S}$} & $10-25$ & $2.5-3.5$ & $0.02-0.1$ & 0.1 & $2 \times 10^{-12}-5 \times 10^{-12}$ \\
\hline & DL: $30-85$ & $0.1-3$ & $5 \times 10^{-3}-2 \times 10^{2}$ & $0.1-0.2$ & $5 \times 10^{-14}-8 \times 10^{-12}$ \\
\hline \multirow{2}{*}{$50^{\circ} \mathrm{N}-65^{\circ} \mathrm{N}$} & $5-25$ & $1-5.5$ & $0.01-0.5$ & $0.4-0.6$ & $10^{-12}-10^{-10}$ \\
\hline & DL: $30-85$ & $0.1-0.7$ & $0.1-30$ & $0.1-0.3$ & $2 \times 10^{-14}-5 \times 10^{-13}$ \\
\hline
\end{tabular}

Abbreviations: DL, detached layer; GDS, global dust storm.

${ }^{\mathrm{a}} v_{\text {eff }}=0.1$ was observed in $\sim 50 \%$ of cases, other values are distributed evenly.

Observations at $L_{S}=211^{\circ}-212^{\circ}, 40^{\circ} \mathrm{S}-55^{\circ} \mathrm{S}$ showed a single layer of medium and large water ice particles $\left(r_{\text {eff }}=1.5-4.5 \mu \mathrm{m}\right)$ located at $20-50 \mathrm{~km}$ with $v_{\text {eff }}=0.1-0.2$ or $0.5-0.6$. Mass loading was $5 \times 10^{-14}-3 \times 10^{-11}$ $\mathrm{g} / \mathrm{cm}^{3}$. Three thin (1-2 km) DLs were observed only once during occultation \#2844, ingress $\left(L_{S}=210.7^{\circ}\right.$, $\left.42^{\circ} \mathrm{S}, 96^{\circ} \mathrm{W}\right)$, at 60,74 , and $83 \mathrm{~km}$. They consisted of $0.1-0.4 \mu \mathrm{m}$ particles with $0.4-6 \mathrm{~cm}^{-3}$ number density and very narrow size distribution ( $v_{\text {eff }}=0.1-0.2$ ), and a mass loading equaled $5 \times 10^{-14}-2 \times 10^{-13} \mathrm{~g} / \mathrm{cm}^{3}$. It is possible that this profile captured water ice clouds in the early stages of formation.

\subsubsection{The Decay of the Global Dust Storm}

The altitude distribution of detected clouds showed two distinct peaks (Figure 9, panel k): the smaller one located at 5-30 $\mathrm{km}$ and the larger one at $30-85 \mathrm{~km}$.

During this period, observations suggest a significant hemispheric dichotomy. We can directly compare observations made at $55^{\circ} \mathrm{N}-65^{\circ} \mathrm{N}$ and at $55^{\circ} \mathrm{S}-65^{\circ} \mathrm{S}$. Two layers of water ice were present in both cases: the main one at 5-25 km (5-40 km) and the detached one at $30-85 \mathrm{~km}(65-85 \mathrm{~km})$ in the northern (southern) hemisphere (Figure 9, panel o). The main layer demonstrated gradual decrease of the radius and mass 
loading with altitude in both hemispheres. However, in the northern hemisphere it consisted of larger particles with a higher number density, resulting in more than an order of magnitude higher mass loading in the north. The main difference between the hemispheres is the altitude and the extent of DLs. In the south, the maximum of water ice was located at $70-80 \mathrm{~km}$ with a thinner aerosol layer extending $5 \mathrm{~km}$ below and above. Below, at altitudes 50-70 km, no aerosols were detected. In the north, the DL was located at 50-70 $\mathrm{km}$, with a thinner aerosol layer extending $15 \mathrm{~km}$ above and $25 \mathrm{~km}$ below, where it connected with the main aerosol layer.

The region at $10^{\circ} \mathrm{S}-40^{\circ} \mathrm{S}$ can be divided into two domains:

1. An almost uniform cloud layer at $10-25 \mathrm{~km}$ with $r_{\text {eff }}=2.5-3.5 \mu \mathrm{m}, N=0.02-0.1 \mathrm{~cm}^{-3}, v_{\text {eff }}=0.1, m=2$ $\times 10^{-12}-5 \times 10^{-12} \mathrm{~g} / \mathrm{cm}^{3}$.

2. A peculiar cloud feature at $30-70 \mathrm{~km}$. Its altitude was raised toward the pole starting from 40 to $60 \mathrm{~km}$ at $20^{\circ} \mathrm{S}$ (Figure 9, panel o), while the particle radius was decreasing. It was formed of larger and more densely populated particles compared to underlying levels (reaching $2-3 \mu \mathrm{m}$ at $30-50 \mathrm{~km}$ at $10^{\circ} \mathrm{S}-20^{\circ} \mathrm{S}$ ), while the effective variance was $0.1-0.2$. The mass loading over the whole feature amounted to $10^{-13}$ $10^{-11} \mathrm{~g} / \mathrm{cm}^{3}$.

Overall, the effective variance remained small in most cases $\left(v_{\text {eff }} \leq 0.2\right)$, becoming larger $\left(v_{\text {eff }} \geq 0.4\right)$ only for $r_{\text {eff }}>3 \mu \mathrm{m}$ or (rarely) for $r_{\text {eff }}<0.2 \mu \mathrm{m}$.

\section{Summary and Discussion}

\subsection{Dust}

Before, during the peak and during the decay of the GDS, dust was detected in 259 out of all observed 267 occultations (97\%). Two hundred and forty-one profiles (90\%) showed both dust and water ice particles together. Eight profiles without dust detection were obtained either before the GDS (three sessions at $L_{S}=$ $183^{\circ}-184^{\circ}$ ) or during the decay phase (five sessions at $L_{S}=243^{\circ}-246^{\circ}, 253^{\circ}-256^{\circ}$ ). In these cases, the lowest sounded altitudes were $20-30 \mathrm{~km}$.

Before the GDS, dust reached higher altitudes at low latitudes, in agreement with Heavens et al. (2011), Kleinböhl et al. (2009), Määttänen et al. (2013), and Smith et al. (2013). During the decay phase, the same distribution was observed, though in the southern hemisphere only, due to narrow latitude coverage in the north. At the peak of the GDS, no clear dependence of the highest dust altitude on latitude can be determined. MCS/MRO was observing the Martian atmosphere using limb scanning over the duration of the GDS in the thermal IR range (463 $\mathrm{cm}^{-1}$ or $21.6 \mu \mathrm{m}$; Kleinböhl et al., 2020). We can qualitatively compare our retrieved dust mass loadings (Figure 8, panels e and j) with MCS dust extinctions (top and middle panels of Figure 2 from Kleinböhl et al., 2020 and accompanying text), noting that the aerosol extinction can be considered as a proxy to aerosol mass loading, as shown by Fedorova et al. (2020). The MCS observations before and during the peak of the GDS performed at local times of $3 \mathrm{a} . \mathrm{m}$. and $3 \mathrm{p}$.m. were related to ACS observations at the morning and at the evening terminators, respectively. Before the GDS, MCS dust top altitude (corresponding to the lowest detectable extinction of $10^{-5} \mathrm{~cm}^{-1}$ ) was $40-45 \mathrm{~km}$ at the equator $\left(20^{\circ} \mathrm{S}-20^{\circ} \mathrm{N}\right)$ and $10-15 \mathrm{~km}$ in polar latitudes $\left(70^{\circ} \mathrm{S}-90^{\circ} \mathrm{S}\right.$ and $\left.70^{\circ} \mathrm{N}-90^{\circ} \mathrm{N}\right)$ both on the dayside and on the nightside. ACS, observing at shorter wavelengths, is more sensitive to smaller dust particles, which extend higher, up to $45-50 \mathrm{~km}$ near the equator $\left(20^{\circ} \mathrm{S}-0^{\circ}\right)$ and $20-30 \mathrm{~km}$ at polar latitudes. During the peak of the GDS, dust was observed up to altitudes of $65-70 \mathrm{~km}$ by MCS and $75-85 \mathrm{~km}$ by ACS. Overall, except for the polar latitudes before the GDS, we can see good qualitative agreement between the two sets of observations.

In the majority of observations, effective radius profiles of dust particles demonstrated a smooth decrease with altitude. The radius of observed dust particles varied from 0.1 to $3.5 \mu \mathrm{m}$. Retrieved effective variances were from 0.1 to 0.6 , with the largest values corresponding to the largest particle sizes $(>2.5 \mu \mathrm{m})$. Our retrieved $r_{\text {eff }}$ appears generally larger than commonly accepted values of $1-2 \mu \mathrm{m}$, see, for example, reviews by Kahre et al. (2017) or Korablev et al. (2005). In particular, Clancy et al. (2003) analyzed emission phase function observations by Thermal Emission Spectrometer (TES) onboard the Mars Global Surveyor spacecraft (MGS) and reported typically 1.5- $\mu \mathrm{m}$ dust particles, with occasionally smaller $(1 \mu \mathrm{m})$ or larger $(1.8-2.5$ 
$\mu \mathrm{m})$ particles. Solar occultation observations by SPICAM/MEx in the near-IR range showed the presence of dust particles with $r_{\text {eff }}=0.5-1 \mu \mathrm{m}$ and $v_{\text {eff }}>0.4$ at 10-30 km (Fedorova et al., 2009). Combined with UV data, these observations pointed to a bimodal dust distribution with $\sim 0.7 \mu \mathrm{m}$ and 0.04-0.07 $\mu \mathrm{m}$ particles (Fedorova et al., 2014). The effective variances for the two modes were assumed to be 0.35 and 0.1 , respectively. Analysis of CRISM/MRO limb scans revealed almost flat vertical profiles of $1 \mu \mathrm{m}$ particles $\left(v_{\text {eff }}=0.3\right.$ used in retrievals) at 10-40 km (Guzewich et al., 2014). Above $50 \mathrm{~km}$, the same data set allowed for the detection of dust $\left(r_{\text {eff }}=0.2-0.7 \mu \mathrm{m}, v_{\text {eff }}=0.3\right.$ ) in $<3 \%$ of cases only (Clancy et al., 2019).

All above listed results refer to the non-GDS period, mostly at altitudes $>10 \mathrm{~km}$. We report larger particle sizes $(>2.5 \mu \mathrm{m})$ at lower altitudes $(\leq 10 \mathrm{~km})$, where the sounding conditions permit. This occurred mostly during the pre-GDS period in polar latitudes, $65^{\circ} \mathrm{S}-75^{\circ} \mathrm{S}$ and $75^{\circ} \mathrm{N}-90^{\circ} \mathrm{N}$. During the peak of the GDS, we have detected particles larger than $3 \mu \mathrm{m}$ in five occultation sessions at altitudes $10-20 \mathrm{~km}$. Such a small amount of observations is explained by the overall increase of optical depth and, as a result, higher sounded altitudes. During the decay phase, large particles were detected in 18 occultation sessions at 5-30 km. These detections are in agreement with past GDS observations, such as Toon et al. (1977) $(\sim 3 \mu \mathrm{m})$ during the decay of 1971 GDS (MY 9) or Clancy et al. (2010), who detected particles of up to $2 \mu \mathrm{m}$ during the 2001 GDS (MY 25). The observations of the 2018 GDS from the surface by the Curiosity Rover yielded $>4 \mu \mathrm{m}$ particles (Lemmon et al., 2019).

\subsection{Water Ice}

Overall, water ice was observed in 249 out of a total of 267 occultations (93\%). Sixteen measurements without clouds were made during the decay phase at middle latitudes $\left(10\right.$ sessions at $56^{\circ} \mathrm{S}-65^{\circ} \mathrm{S}$ and 6 sessions at $\left.57^{\circ} \mathrm{N}-60^{\circ} \mathrm{N}\right)$.

Before the GDS, we see water ice at $0-40 \mathrm{~km}$ at the poles and at $30-70 \mathrm{~km}$ as DLs at low latitudes, $20^{\circ} \mathrm{S}-0^{\circ} \mathrm{S}$. Clouds were also seen at $10-30 \mathrm{~km}$ between $10^{\circ} \mathrm{S}$ and $20^{\circ} \mathrm{S}$, but not at $0^{\circ} \mathrm{S}-10^{\circ} \mathrm{S}$, in agreement with MCS/ MRO observations analyzed in Heavens et al. (2011). Their zonally averaged water ice density-scaled opacity maps at $L_{S} 180^{\circ}$ show water ice at $5-40 \mathrm{~km}$ at $60^{\circ} \mathrm{S}-90^{\circ} \mathrm{S}$ and $60^{\circ} \mathrm{N}-90^{\circ} \mathrm{N}$ at both 3 p.m. and 3 a.m. (panels g and h of Figure 3 in Heavens et al., 2011). MCS low-latitude data show differences between day and night. Our morning terminator observations at $0^{\circ} \mathrm{S}-20^{\circ} \mathrm{S}$ reveal the presence of water ice DLs at $40-60 \mathrm{~km}$, in agreement with MCS night observations (panel g of Figure 3 in Heavens et al., 2011).

Our results on water ice clouds can be analyzed together with simultaneous water vapor measurements by ACS NIR. Figure 10 (panels a-c) shows temperature and water vapor profiles from NIR spectra (Fedorova et al., 2020) and water ice mass loading retrieved as described above. Before the GDS, water ice particles at high and middle latitudes were found where the water contents and the temperature were low $(<1 \mathrm{ppm}$ vmr of water and $T \leq 150 \mathrm{~K}$ ), suggesting that nearly all water vapor has condensed. At low latitudes, water ice clouds coexisted with higher mixing ratios of water vapor (50-100 ppm) and higher temperatures $(170-180 \mathrm{~K})$.

During the GDS peak, we observed an intense and abrupt appearance of high altitude (50-100 km) DLs consisting of submicron $(0.1-0.8 \mu \mathrm{m})$ water ice particles. The high-altitude ice clouds were also observed with the ACS MIR channel (Stcherbinine et al., 2020). During the 2001 GDS (MY 25), TES/MGS also observed small $\left(r_{\text {eff }} \leq 1 \mu \mathrm{m}\right.$ ) water ice particles at 60-80 km (Clancy et al., 2010). Such rapid formation of water ice aerosols during the dust storm can be explained by an increase in the high-altitude water vapor (panels a and d of Figure 10; Aoki et al., 2019, Neary et al., 2020, Vandaele et al., 2019; see also Fedorova et al., 2018; Shaposhnikov et al., 2019 for the 2007 GDS) in the presence of condensation nuclei (panels a and d of Figure 8).

During the GDS decay, the northern hemisphere water ice corresponded to local minima in water vapor vmr and temperature (panels g, h, i of Figure 10). In the southern hemisphere, water vapor peaked at 40-60 km at $10^{\circ} \mathrm{S}-65^{\circ} \mathrm{S}$. Clouds were located above and below this maximum, suggesting a depletion of water vapor due to condensation. The observed increase of water vapor abundance and temperature at higher latitudes corresponds to the decrease in water ice mass loading. Observations made during the GDS decay are in agreement with MCS results at $L_{S}=270^{\circ}$ for a non-GDS year (panels g, h of Figure 7 in Heavens et al., 2011), 
(a)

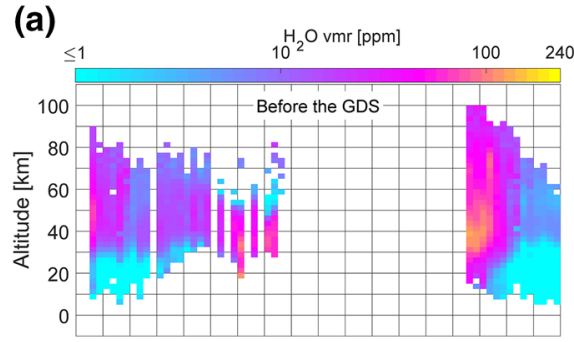

(d)

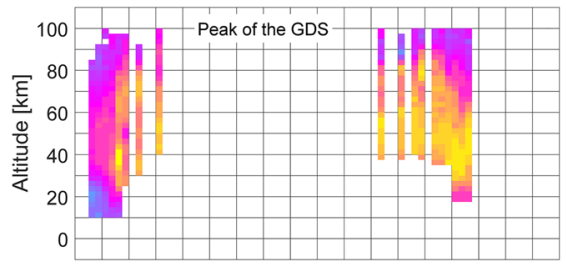

(g)

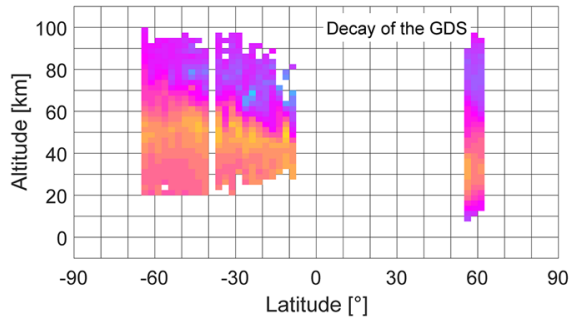

(b)

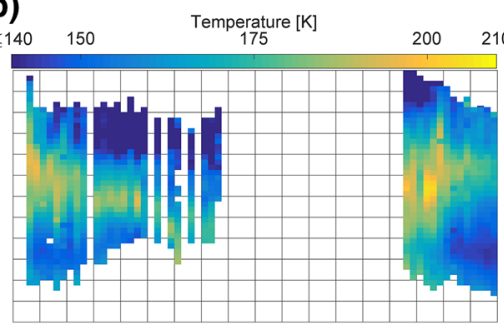

(e)

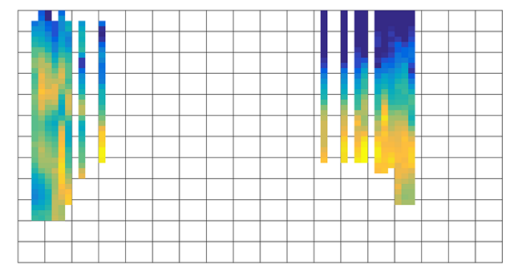

(h)

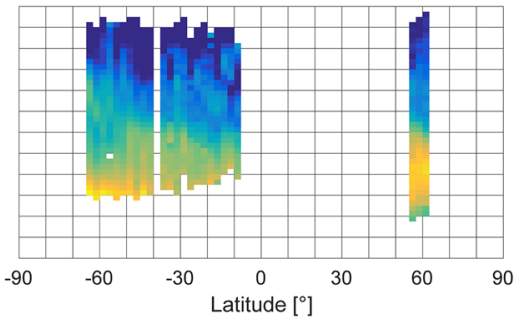

(c)

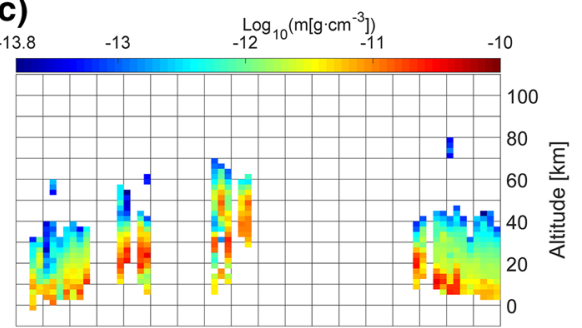

(f)

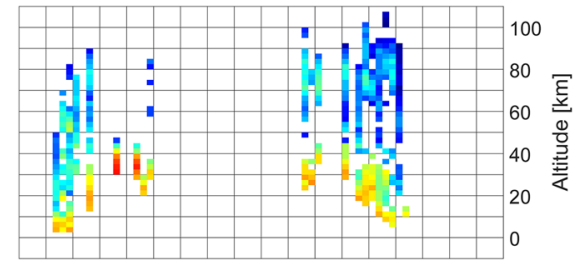

(i)

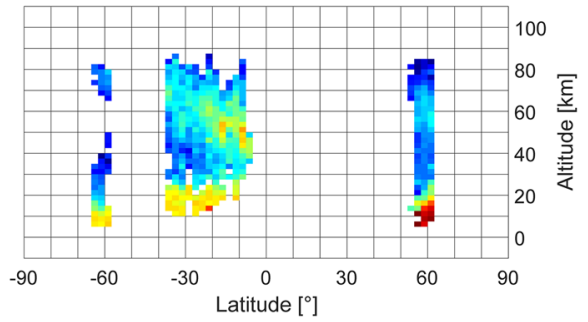

Figure 10. Latitude-altitude maps of temperature (panels a, d, g), water vapor volume mixing ratio (panels b, e, h), water ice mass loading (panels c, f, i) averaged in three $L_{S}$ bins: before the GDS (panels a-c), during the onset and peak of the GDS (panels d-f), and during the decay of the GDS (panels g-i).

although we find mid-latitude DLs at higher altitudes. This difference could be explained by a more intense vertical transport of water vapor during the GDS.

In the majority of observations, effective radius profiles of water ice particles gradually decreased with altitude both in the main cloud layer and the DL. The radius of observed water ice particles varied in the range $r_{\text {eff }}=0.1-5.5 \mu \mathrm{m}$. The effective variance was highly variable within our full considered range of 0.1-0.6; the largest valued correspond to the largest particle sizes $\left(r_{\text {eff }}>3.5 \mu \mathrm{m}\right)$, and, in some cases of high altitude water ice clouds, to very small particles $\left(r_{\text {eff }}<0.2 \mu \mathrm{m}\right)$. Similar to dust particles, the size of ice particles during the GDS was larger. TES/MGS emission phase function observations identified two types of water ice cloud with $r_{\text {eff }}=1-2 \mu \mathrm{m}$ and $r_{\text {eff }}=3-4 \mu \mathrm{m}$ particles (Clancy et al., 2003). The larger type was associated with the aphelion cloud belt (Clancy et al., 1996; Montmessin et al., 2004). SPICAM-IR/MEx solar occultations during the northern fall of MY $28\left(L_{S}=130^{\circ}-160^{\circ}\right)$ revealed $0.5-1 \mu \mathrm{m}$ particles (if assumed to be of water ice nature) at $15-30 \mathrm{~km}$ and $0.1-0.3 \mu \mathrm{m}$ particles at 50-60 km (Fedorova et al., 2009), while in the northern summer of MY $29\left(L_{S}=56^{\circ}-97^{\circ}\right) 0.7-1.2 \mu \mathrm{m}$ particles were observed at 10-50 km (Fedorova et al., 2014). CRISM/MRO limb observations demonstrated the presence of water ice particles with an effective radius ranging from $1 \mu \mathrm{m}$ up to $3 \mu \mathrm{m}$ at low latitudes at $L_{S}=180^{\circ}-210^{\circ}$ (Guzewich \& Smith, 2019), in agreement with our results.

We note that all observations taken at $75^{\circ} \mathrm{S}-90^{\circ} \mathrm{S}$ before the GDS (eight occultation sessions) below $10 \mathrm{~km}$ resulted in 1-2 $\mu \mathrm{m}$ dust particles and very large $(3.5-5.5 \mu \mathrm{m})$ water ice particles, while measurements at $60^{\circ} \mathrm{S}-75^{\circ} \mathrm{S}$ at the same altitudes gave $1.5-3.5 \mu \mathrm{m}$ and $1-2.5 \mu \mathrm{m}$ for dust and water ice, respectively. Also, the water ice number density was an order of magnitude higher in the latter case. The discussed observations took place in the beginning of the southern spring. At $75^{\circ} \mathrm{S}-90^{\circ} \mathrm{S}$, still cold polar winter conditions, associated with an ample supply of water vapor above $30 \mathrm{~km}$ (see panel a of Figure 10), develop dense water clouds below. General circulation modeling predicts even larger water ice particles $(>6 \mu \mathrm{m}$; Figure 8 in Montmessin et al., 2004). At $60^{\circ} \mathrm{S}-75^{\circ} \mathrm{S}$, we might have captured the sublimation of the polar cap, freeing trapped dust particles, including the large ones. As effective radius is an integral of $r^{3}$ over the size distribution, even the small relative quantity of large particles will increase the resulting effective radius. 
Table 4

Statistics on Detected Detached Layers

\begin{tabular}{|c|c|c|c|c|c|c|c|}
\hline \multicolumn{5}{|c|}{ Number of occultations } & \multicolumn{3}{|c|}{ DL composition } \\
\hline Total & $\begin{array}{c}\text { With DL(s) } \\
(\%)\end{array}$ & $\begin{array}{c}\text { With a single } \\
\text { DL (\%) }\end{array}$ & $\begin{array}{l}\text { With double } \\
\text { DLs (\%) }\end{array}$ & $\begin{array}{c}\text { With triple } \\
\text { DLs }(\%)\end{array}$ & $\begin{array}{c}\text { Water ice } \\
(\%)\end{array}$ & Dust $(\%)$ & Total \\
\hline \multicolumn{8}{|c|}{ Before the GDS } \\
\hline \multicolumn{8}{|c|}{$L_{S}=180^{\circ}-195^{\circ}$ in the northern hemisphere and $L_{S}=180^{\circ}-198^{\circ}$ in the southern hemisphere } \\
\hline 61 & 21 (34) & $13(21)$ & $5(8)$ & $3(5)$ & 27 (84) & $5(16)$ & 32 \\
\hline \multicolumn{8}{|c|}{ The outbreak and the peak of the GDS } \\
\hline \multicolumn{8}{|c|}{$L_{S}=196^{\circ}-212^{\circ}$ in the northern hemisphere and $L_{S}=198^{\circ}-212^{\circ}$ in the southern hemisphere } \\
\hline 32 & $29(91)$ & $15(47)$ & $10(31)$ & $4(13)$ & $28(60)$ & $19(40)$ & 47 \\
\hline \multicolumn{8}{|c|}{ The decay of the GDS. $L_{S}=242^{\circ}-255^{\circ}$} \\
\hline 165 & $84(51)$ & $62(38)$ & $19(11)$ & $3(2)$ & $90(83)$ & $19(17)$ & 109 \\
\hline
\end{tabular}

Abbreviations: DL, detached layer; GDS, global dust storm.

\subsection{Detached Layers}

Here, we present a summary of encountered DLs (Table 4), leaving a detailed analysis of their properties for a dedicated study. Before the GDS, DLs were observed in 34\% of occultations, with double or triple DLs during one occultation detected in $13 \%$ of observations. The majority of DL were composed of water ice particles (84\%). During the GDS, the frequency of DLs observations increased to $91 \%$, and in nearly half of the cases, we saw multiple DLs. The number of dust DLs increased to 40\%. During the GDS decay, we saw DLs in $51 \%$ of occultations, while the frequency of multiple DLs and their composition reverted to the pre-GDS state.

DLs, located above the main aerosol layer, were always composed of water ice. In some cases, the particles within a DL were significantly larger than below and above, while in others the particle size was similar but the number density was several times greater in the DL. We note this variety for both types of aerosols.

A comprehensive study of DLs based on SPICAM/MEx stellar occultations in 2004-2011, including the 2007 GDS (MY 28), is given by Määttänen et al. (2013). The DLs were detected in nearly half of occultation profiles, mostly above the main aerosol layer. Sometimes, the layers appeared as structures inside the main layer. Multiple (up to three) layers were observed in 13\% of cases. Although UV observations by Määttänen et al. (2013) do not distinguish between dust and ice particles, they concluded that the DLs were formed of larger or equal particles compared to the surroundings, in agreement with our results. They also speculated that the larger particles in DLs are predominantly composed of water ice, a concept not confirmed by our observations, as we saw larger particles of both types.

\section{Conclusions}

In this study, we present the analysis of aerosol properties and abundances in the Martian atmosphere before $\left(L_{S} \leq 195^{\circ}\right.$ in the north and $L_{S} \leq 198^{\circ}$ in the south), during the peak $\left(L_{S} 196^{\circ}-212^{\circ}\right.$ in the north and $L_{S} 198^{\circ}-212^{\circ}$ in the south) and during the decay $\left(L_{S} 242^{\circ}-255^{\circ}\right)$ phases of the 2018 (MY 34) GDS using ACS TIRVIM and NIR solar occultation observations. Usage of high $\left(>10^{3}\right)$ SNR spectra measured in an unprecedentedly wide (for solar occultations) spectral region $(0.8-6 \mu \mathrm{m})$ that includes a water ice absorption band at $\sim 3 \mu \mathrm{m}$ allows unambiguous simultaneous detection of water ice and dust aerosols from 0 to $100 \mathrm{~km}$ as well as retrieval of respective particle sizes, distribution widths, and number densities. The key results of the study are as follows:

1. In most of the observations, the particle size of dust decreased with altitude. Dust effective radius ranged from 0.1 to $3.5 \mu \mathrm{m}$, with the largest particles observed at $0-10 \mathrm{~km}$ before and after the GDS. Number density was confined between $10^{-2}-10^{2} \mathrm{~cm}^{-3}$. The effective variance was mostly $0.1-0.2$, reaching $0.5-0.6$ for $>2.5 \mu \mathrm{m}$ particles. Mass loading was observed in the range $10^{-13}-5 \times 10^{-11} \mathrm{~g} / \mathrm{cm}^{3}$. 
2. In the case of water ice, the same general trend of decreasing particle size with the altitude was observed. We detected particles with $0.1-5.5 \mu \mathrm{m}$ effective radii, the largest particles, just as for dust, found below 10 $\mathrm{km}$ before the onset and during the decay phase of the GDS. Number density was confined between $10^{-2}$ and $10^{2} \mathrm{~cm}^{-3}$. The effective variance was small (0.1-0.2) for most of the observations, reaching $0.5-0.6$ for 3-5.5 $\mu \mathrm{m}$ particles, and, in some cases, for $<0.5 \mu \mathrm{m}$ particles. Mass loading was observed in the range $10^{-14}-10^{-10} \mathrm{~g} / \mathrm{cm}^{3}$.

3. At the peak of the GDS, dust reached altitudes up to $85 \mathrm{~km}$. The most frequently observed effective radius was $1-2 \mu \mathrm{m}$ with $0.1-1 \mathrm{~cm}^{-3}$ number density and 0.1 effective variance. Detached layers formed of 0.1-1 $\mu \mathrm{m}$ water ice particles were observed at high altitudes $(50-100 \mathrm{~km})$ during this period. Below the detached layer, at $0-50 \mathrm{~km}$, the main water ice layer of 1-4 $\mu \mathrm{m}$ particles was observed.

4. At the beginning of the southern summer season $\left(L_{S}=240^{\circ}-245^{\circ}\right)$, water ice detached layers were observed at $30-70 \mathrm{~km}$ at $10^{\circ} \mathrm{S}-40^{\circ} \mathrm{S}$. The altitude of water ice aerosols increased when moving poleward following the trend of water vapor and temperature.

5. Detached layers were present in half of our observations, with double and triple detached layers observed during a single occultation in some cases. The majority of the observed detached layers consisted of water ice particles. During the GDS, the number of detached dust layers increased several fold. For both dust and ice, the particles in the detached layer may be larger than the particles below and above, or their number density may be several times greater but have approximately the same effective radius.

To conclude, in this study, we show that the MY 34 GDS has noticeably modified the vertical and spatial distribution of dust and water ice aerosols and their microphysical properties, lifting the dust up to $85 \mathrm{~km}$ and prompting water ice clouds at altitudes up to $100 \mathrm{~km}$ during the peak of the GDS.

\section{Data Availability Statement}

Raw ACS data are available from ESA's Planetary Science Archive at https://archives.esac.esa.int/ $\mathrm{psa} / \#$ !Table\%20View/ACS=instrument. The effective radius, number density, effective variance, and mass loading profiles for dust and water ice retrieved from the ACS measurements and analyzed in this article are available at http://exomars.cosmos.ru/Aerosols from ACS during 2018 GDS ieQivhYGPB2KrntNGLo4Y/ and from Luginin (2020).

\section{Acknowledgments}

ExoMars is a space mission of ESA and Roscosmos. The ACS experiment is led by IKI, the Space Research Institute in Moscow, assisted by LATMOS in France. The science operations of ACS are funded by Roscosmos and ESA. We are grateful to Michael Wolff, an anonymous reviewer, and Journal of Geophysical Research: Planets editorial board whose comments helped to improve this paper. The early retrievals in 2019 were supported by Ministry of Science and Education of the Russian government. M. Luginin, A. Fedorova, N. Ignatiev, A. Trokhimovskiy, and O. Korablev acknowledge RSF funding of Sections 4 and 5 under grant number 20-42-09035. F. Montmessin acknowledges funding from CNES and ANR (PRCI, CE31 AAPG2019).

\section{References}

Aoki, S., Vandaele, A. C., Daerden, F., Villanueva, G. L., Liuzzi, G., Thomas, I. R., et al. (2019). Water vapor vertical profiles on Mars in dust storms observed by TGO/NOMAD. Journal of Geophysical Research: Planets, 124, 3482-3497. https://doi.org/10.1029/2019JE006109

Bertrand, T., Wilson, R. J., Kahre, M. A., Urata, R., \& Kling, A. (2020). Simulation of the 2018 global dust storm on Mars using the NASA Ames Mars GCM: A multi-tracer approach. Journal of Geophysical Research: Planets, 125, 0-2. https://doi.org/10.1029/2019JE006122

Bibring, J.-P., Soufflot, A., Berthé, M., Langevin, Y., Gondet, B., Drossart, P., et al. (2004). OMEGA: Observatoire pour la Minéralogie, l'Eau, les Glaces et l'Activité. In A. Wilson (Ed.), Mars Express: The scientific payload, ESA-1240 (pp. 37-49). European Space Agency.

Cantor, B. A. (2007). MOC observations of the 2001 Mars planet-encircling dust storm. Icarus, 186(1), 60-96. https://doi.org/10.1016/j. icarus.2006.08.019

Chassefiere, E., Blamont, J. E., Krasnopolsky, V. A., Korablev, O., Atreya, S. K., \& West, R. A. (1992). Vertical structure and size distributions of Martian aerosols from solar occultation measurements. Icarus, 97(1), 46-69. https://doi.org/10.1016/0019-1035(92)90056-D

Clancy, R. T., Grossman, A. W., Wolff, M. J., James, P. B., Rudy, D. J., Billawala, Y. N., et al. (1996). Water vapor saturation at low altitudes around Mars aphelion: A key to Mars climate? Icarus, 122(1), 36-62. https://doi.org/10.1006/icar.1996.0108

Clancy, R. T., Sandor, B. J., Wolff, M. J., Christensen, P. R., Smith, M. D., Pearl, J. C., et al. (2000). An intercomparison of ground-based millimeter, MGS TES, and Viking atmospheric temperature measurements: Seasonal and interannual variability of temperatures and dust loading in the global Mars atmosphere. Journal of Geophysical Research, 105(E4), 9553-9571. https://doi.org/10.1029/1999JE001089

Clancy, R. T., Wolff, M. J., \& Christensen, P. R. (2003). Mars aerosol studies with the MGS TES emission phase function observations: Optical depths, particle sizes, and ice cloud types versus latitude and solar longitude. Journal of Geophysical Research, 108(E9), 5098. https://doi.org/10.1029/2003JE002058

Clancy, R. T., Wolff, M. J., Smith, M. D., Kleinböhl, A., Cantor, B. A., Murchie, S. L., et al. (2019). The distribution, composition, and particle properties of Mars mesospheric aerosols: An analysis of CRISM visible/near-IR limb spectra with context from near-coincident MCS and MARCI observations. Icarus, 328(March), 246-273. https://doi.org/10.1016/j.icarus.2019.03.025

Clancy, R. T., Wolff, M. J., Whitney, B. A., Cantor, B. A., Smith, M. D., \& McConnochie, T. H. (2010). Extension of atmospheric dust loading to high altitudes during the 2001 Mars dust storm: MGS TES limb observations. Icarus, 207(1), 98-109. https://doi.org/10.1016/j. icarus.2009.10.011

Clapp, M. L., Worsnop, D. R., \& Miller, R. E. (1995). Frequency-dependent optical constants of water ice obtained directly from aerosol extinction spectra. The Journal of Physical Chemistry, 99(17), 6317-6326. http://doi.org/10.1021/j100017a010

Conrath, B. J. (1975). Thermal structure of the Martian atmosphere during the dissipation of the dust storm of 1971. Icarus, 24(1), 36-46. https://doi.org/10.1016/0019-1035(75)90156-6 
Fedorova, A., Bertaux, J.-L., Betsis, D., Montmessin, F., Korablev, O., Maltagliati, L., \& Clarke, J. (2018). Water vapor in the middle atmosphere of Mars during the 2007 global dust storm. Icarus, 300, 440-457. https://doi.org/10.1016/j.icarus.2017.09.025

Fedorova, A., Korablev, O., Bertaux, J.-L., Rodin, A. V., Montmessin, F., Belyaev, D., \& Reberac, A. (2009). Solar infrared occultation observations by SPICAM experiment on Mars-Express: Simultaneous measurements of the vertical distributions of $\mathrm{H} 2 \mathrm{O}$, $\mathrm{CO} 2$ and aerosol. Icarus, 200(1), 96-117. https://doi.org/10.1016/j.icarus.2008.11.006

Fedorova, A. A., Montmessin, F., Korablev, O., Luginin, M., Trokhimovskiy, A., Belyaev, D. A., et al. (2020). Stormy water on Mars: The distribution and saturation of atmospheric water during the dusty season. Science, 367(6475), 297-300. https://doi.org/10.1126/science. aay9522

Fedorova, A., Montmessin, F., Rodin, A. V., Korablev, O., Määttänen, A., Maltagliati, L., \& Bertaux, J.-L. (2014). Evidence for a bimodal size distribution for the suspended aerosol particles on Mars. Icarus, 231, 239-260. https://doi.org/10.1016/j.icarus.2013.12.015

Formisano, V., Angrilli, F., Arnold, G., Atreya, S., Bianchini, G., Biondi, D., et al. (2005). The Planetary Fourier Spectrometer (PFS) onboard the European Mars Express mission. Planetary and Space Science, 53(10), 963-974. https://doi.org/10.1016/j.pss.2004.12.006

Guzewich, S. D., Lemmon, M. T., Smith, C. L., Martínez, G., Vicente-Retortillo, Á., Newman, C. E., et al. (2019). Mars Science Laboratory observations of the 2018/Mars year 34 global dust storm. Geophysical Research Letters, 46(1), 71-79. https://doi.org/10.1029/2018GL080839

Guzewich, S. D., \& Smith, M. D. (2019). Seasonal variation in Martian water ice cloud particle size. Journal of Geophysical Research: Planets, 124(2), 636-643. https://doi.org/10.1029/2018JE005843

Guzewich, S. D., Smith, M. D., \& Wolff, M. J. (2014). The vertical distribution of Martian aerosol particle size. Journal of Geophysical Research: Planets, 119(12), 2694-2708. https://doi.org/10.1002/2014JE004704

Guzewich, S. D., Toigo, A. D., Richardson, M. I., Newman, C. E., Talaat, E. R., Waugh, D. W., \& McConnochie, T. H. (2013). The impact of a realistic vertical dust distribution on the simulation of the Martian General Circulation. Journal of Geophysical Research: Planets, 118(5), 980-993. https://doi.org/10.1002/jgre.20084

Haberle, R. M., Leovy, C. B., \& Pollack, J. B. (1982). Some effects of global dust storms on the atmospheric circulation of Mars. Icarus, 50(2-3), 322-367. https://doi.org/10.1016/0019-1035(82)90129-4

Hansen, J. E., \& Travis, L. D. (1974). Light scattering in planetary atmospheres. Space Science Reviews, 16(4), 527-610. https://doi. org/10.1007/BF00168069

Heavens, N. G., McCleese, D. J., Richardson, M. I., Kass, D. M., Kleinböhl, A., \& Schofield, J. T. (2011). Structure and dynamics of the Martian lower and middle atmosphere as observed by the Mars Climate Sounder: 2. Implications of the thermal structure and aerosol distributions for the mean meridional circulation. Journal of Geophysical Research, 116(E1), E01010. https://doi.org/10.1029/2010JE003713

Kahre, M. A., Murphy, J. R., Newman, C. E., Wilson, R. J., Cantor, B. A., Lemmon, M. T., \& Wolff, M. (2017). The Mars dust cycle. In R. M. Haberle, R. T. Clancy, F. Forget, M. D. Smith, \& R. W. Zurek (Eds.), The atmosphere and climate of Mars (pp. 295-337). Cambridge University Press. https://doi.org/10.1017/9781139060172.010

Kleinböhl, A., Schofield, J. T., Kass, D. M., Abdou, W. A., Backus, C. R., Sen, B., et al. (2009). Mars Climate Sounder limb profile retrieval of atmospheric temperature, pressure, and dust and water ice opacity. Journal of Geophysical Research, 114(E10). https://doi. org/10.1029/2009JE003358

Kleinböhl, A., Spiga, A., Kass, D. M., Shirley, J. H., Millour, E., Montabone, L., \& Forget, F. (2020). Diurnal variations of dust during the 2018 global dust storm observed by the Mars Climate Sounder. Journal of Geophysical Research: Planets, 125. https://doi. org/10.1029/2019JE006115

Korablev, O. I., Krasnopolsky, V. A., Rodin, A. V., \& Chassefière, E. (1993). Vertical structure of Martian dust measured by solar infrared occultations from the Phobos spacecraft. Icarus, 102(1), 76-87. https://doi.org/10.1006/icar.1993.1033

Korablev, O., Montmessin, F., Trokhimovskiy, A., Fedorova, A., Shakun, A. V., Grigoriev, A. V., et al. (2018). The atmospheric chemistry suite (ACS) of three spectrometers for the ExoMars 2016 trace gas orbiter. Space Science Reviews, 214(1), 7. https://doi.org/10.1007/ s11214-017-0437-6

Korablev, O., Moroz, V. I., Petrova, E. V., \& Rodin, A. V. (2005). Optical properties of dust and the opacity of the Martian atmosphere. Advances in Space Research, 35(1), 21-30. https://doi.org/10.1016/j.asr.2003.04.061

Lemmon, M. T., Guzewich, S. D., McConnochie, T., Vicente-Retortillo, A., Martínez, G., Smith, M. D., et al. (2019). Large dust aerosol sizes seen during the 2018 Martian global dust event by the curiosity rover. Geophysical Research Letters, 46(16), 9448-9456. https://doi. org/10.1029/2019GL084407

Leovy, C. B., \& Zurek, R. W. (1979). Thermal tides and Martian dust storms: Direct evidence for coupling. Journal of Geophysical Research, 84(B6), 2956. https://doi.org/10.1029/JB084iB06p02956

Luginin, M. (2020). Aerosols from ACS during 2018 GDS. Mendeley Data, v1. http://dx.doi.org/10.17632/rkszdmpdcy.1

Luginin, M. S., Fedorova, A., Belyaev, D., Montmessin, F., Wilquet, V., Korablev, O., et al. (2016). Aerosol properties in the upper haze of Venus from SPICAV IR data. Icarus, 277, 154-170. https://doi.org/10.1016/j.icarus.2016.05.008

Määttänen, A., Listowski, C., Montmessin, F., Maltagliati, L., Reberac, A., Joly, L., \& Bertaux, J.-L. (2013). A complete climatology of the aerosol vertical distribution on Mars from MEx/SPICAM UV solar occultations. Icarus, 223(2), 892-941. https://doi.org/10.1016/j. icarus.2012.12.001

Madeleine, J.-B., Forget, F., Spiga, A., Wolff, M. J., Montmessin, F., Vincendon, M., et al. (2012). Aphelion water-ice cloud mapping and property retrieval using the OMEGA imaging spectrometer onboard Mars Express. Journal of Geophysical Research, 117(E11). https:// doi.org/10.1029/2011JE003940

Millour, E., Forget, F., Spiga, A., Vals, M., Zakharov, V., Montabone, L., et al. (2018). The Mars climate database (version 5.3). Paper presented at the Mars science Workshop "From Mars Express to ExoMars". Madrid, Spain: ESAC.

Mishchenko, M. I., Dlugach, J. M., Yanovitskij, E. G., \& Zakharova, N. T. (1999). Bidirectional reflectance of flat, optically thick particulate layers: An efficient radiative transfer solution and applications to snow and soil surfaces. Journal of Quantitative Spectroscopy and Radiative Transfer, 63(2-6), 409-432. https://doi.org/10.1016/S0022-4073(99)00028-X

Montabone, L., Forget, F., Millour, E., Wilson, R. J., Lewis, S. R., Cantor, B., et al. (2015). Eight-year climatology of dust optical depth on Mars. Icarus, 251, 65-95. https://doi.org/10.1016/j.icarus.2014.12.034

Montmessin, F., Forget, F., Rannou, P., Cabane, M., \& Haberle, R. M. (2004). Origin and role of water ice clouds in the Martian water cycle as inferred from a general circulation model. Journal of Geophysical Research, 109(E10), E10004. https://doi.org/10.1029/2004JE002284

Montmessin, F., Korablev, O., Lefèvre, F., Bertaux, J.-L., Fedorova, A., Trokhimovskiy, A., et al. (2017). SPICAM on Mars express: A 10 year in-depth survey of the Martian atmosphere. Icarus, 297, 195-216. https://doi.org/10.1016/j.icarus.2017.06.022

Montmessin, F., Quémerais, E., Bertaux, J.-L., Korablev, O., Rannou, P., \& Lebonnois, S. (2006). Stellar occultations at UV wavelengths by the SPICAM instrument: Retrieval and analysis of Martian haze profiles. Journal of Geophysical Research, 111(E9), E09S09. https://doi. org/10.1029/2005JE002662 
Montmessin, F., Rannou, P., \& Cabane, M. (2002). New insights into Martian dust distribution and water-ice cloud microphysics. Journal of Geophysical Research, 107(E6), 5037. https://doi.org/10.1029/2001JE001520

Murchie, S., Arvidson, R., Bedini, P., Beisser, K., Bibring, J.-P., Bishop, J., et al. (2007). Compact reconnaissance imaging spectrometer for Mars (CRISM) on Mars reconnaissance orbiter (MRO). Journal of Geophysical Research, 112(E5), E05S03. https://doi. org/10.1029/2006JE002682

Navarro, T., Forget, F., Millour, E., \& Greybush, S. J. (2014). Detection of detached dust layers in the Martian atmosphere from their thermal signature using assimilation. Geophysical Research Letters, 41(19), 6620-6626. https://doi.org/10.1002/2014GL061377

Neary, L., Daerden, F., Aoki, S., Whiteway, J., Clancy, R. T., Smith, M., et al. (2020). Explanation for the increase in high altitude water on Mars observed by NOMAD during the 2018 global dust storm. Geophysical Research Letters, 47. https://doi.org/10.1029/2019gl084354

Pearl, J. C., Smith, M. D., Conrath, B. J., Bandfield, J. L., \& Christensen, P. R. (2001). Observations of Martian ice clouds by the Mars global surveyor thermal emission spectrometer: The first Martian year. Journal of Geophysical Research, 106(E6), 12325-12338. https://doi. org/10.1029/1999JE001233

Richardson, M. I., \& Wilson, R. J. (2002). Investigation of the nature and stability of the Martian seasonal water cycle with a general circulation model. Journal of Geophysical Research, 107(E5), 5031. https://doi.org/10.1029/2001JE001536

Rodgers, C. D. (2000). Inverse methods for atmospheric sounding: Theory and practice. River Edge, NJ: World Scientific.

Shakun, A., Ignatiev, I., Luginin, M., Grigoriev, A., Moshkin, B., Grassi, D., et al. (2018). ACS/TIRVIM: Calibration and first results. Proceedings SPIE 10765, Infrared Remote Sensing and Instrumentation XXVI, 107650E. https://doi.org/10.1117/12.2322163

Shaposhnikov, D., Medvedev, A., Rodin, A., \& Hartogh, P. (2019). Seasonal water "pump" in the atmosphere of Mars: vertical transport to the thermosphere. Geophysical Research Letters, 46(8), 4161-4169. https://doi.org/10.1029/2019GL082839

Shaposhnikov, D. S., Rodin, A. V., Medvedev, A. S., Fedorova, A., Kuroda, T., \& Hartogh, P. (2018). Modeling the hydrological cycle in the atmosphere of Mars: Influence of a bimodal size distribution of aerosol nucleation particles. Journal of Geophysical Research: Planets, 123(2), 508-526. https://doi.org/10.1002/2017JE005384

Shirley, J. H., Kleinböhl, A., Kass, D. M., Steele, L. J., Heavens, N. G., Suzuki, S., et al. (2019). Rapid expansion and evolution of a regional dust storm in the Acidalia Corridor during the initial growth phase of the Martian global dust storm of 2018. Geophysical Research Letters, 47. https://doi.org/10.1029/2019GL084317

Smith, M. D. (2008). Spacecraft observations of the Martian atmosphere. Annual Review of Earth and Planetary Sciences, 36(1), 191-219. https://doi.org/10.1146/annurev.earth.36.031207.124334

Smith, M. D. (2009). THEMIS observations of Mars aerosol optical depth from 2002-2008. Icarus, 202(2), 444-452. https://doi.org/10.1016/j. icarus.2009.03.027

Smith, M. D., Wolff, M. J., Clancy, R. T., Kleinböhl, A., \& Murchie, S. L. (2013). Vertical distribution of dust and water ice aerosols from CRISM limb-geometry observations. Journal of Geophysical Research: Planets, 118(2), 321-334. https://doi.org/10.1002/jgre.20047

Stcherbinine, A., Vincendon, M., Montmessin, F., Wolff, M. J., Korablev, O., Fedorova, A., et al. (2020). Martian water ice clouds during the 2018 global dust storm as observed by the ACS-MIR channel onboard the trace gas orbiter. Journal of Geophysical Research: Planets, 125(3), 1-38. https://doi.org/10.1029/2019JE006300

Toon, O. B., Pollack, B. J., \& Sagan, C. (1977). Physical properties of the particles composing the Martian dust storm of 1971-1972. Icarus, 30(4), 663-696. https://doi.org/10.1016/0019-1035(77)90088-4

Trokhimovskiy, A., Korablev, O., Ivanov, Y., Syniavskyi, I., Montmessin, F., \& Fedorova, A. (2017). High resolution middle infrared spectrometer, a part of atmospheric chemistry suite (ACS) for EXOMARS 2016 trace gas orbiter. Proceedings of SPIE 10563, International Conference on Space Optics-ICSO, 2014, 105634L. https://doi.org/10.1117/12.2304234

Vago, J., Witasse, O., Svedhem, H., Baglioni, P., Haldemann, A., Gianfiglio, G., et al. (2015). ESA ExoMars program: The next step in exploring Mars. Solar System Research, 49(7), 518-528. https://doi.org/10.1134/S0038094615070199

Vandaele, A. C., Korablev, O., Daerden, F., Aoki, S., Thomas, I. R., Altieri, F., et al. (2019). Martian dust storm impact on atmospheric H2O and D/H observed by ExoMars Trace Gas Orbiter. Nature, 568(7753), 521-525. https://doi.org/10.1038/s41586-019-1097-3

Vincendon, M., Langevin, Y., Poulet, F., Bibring, J., Gondet, B., \& Jouglet, D. (2008). Dust aerosols above the south polar cap of Mars as seen by OMEGA. Icarus, 196(2), 488-505. https://doi.org/10.1016/j.icarus.2007.11.034

Wang, H., \& Richardson, M. I. (2015). The origin, evolution, and trajectory of large dust storms on Mars during Mars years 24-30 (19992011). Icarus, 251, 112-127. https://doi.org/10.1016/j.icarus.2013.10.033

Warren, S. G., \& Brandt, R. E. (2008). Optical constants of ice from the ultraviolet to the microwave: A revised compilation. Journal of Geophysical Research, 113(D14), D14220. https://doi.org/10.1029/2007JD009744

Wilson, R. J., Lewis, S. R., Montabone, L., \& Smith, M. D. (2008). Influence of water ice clouds on Martian tropical atmospheric temperatures. Geophysical Research Letters, 35(7), L07202. https://doi.org/10.1029/2007GL032405

Wolff, M. J., Smith, M., Clancy, R. T., Arvidson, R., Kahre, M., Seelos, F., et al. (2009). Wavelength dependence of dust aerosol single scattering albedo as observed by the Compact Reconnaissance Imaging Spectrometer. Journal of Geophysical Research, 114(6), E00D04. https://doi.org/10.1029/2009JE003350

Zurek, R. W. (1982). Martian great dust storms: An update. Icarus, 50(2-3), 288-310. https://doi.org/10.1016/0019-1035(82)90127-0 